\title{
Hepatites virais no contexto brasileiro: uma revisão integrativa
}

\author{
Viral hepatitis in the brazilian context: an integrative review \\ Hepatitis viral en el contexto brasileño: una revisión integrante
}

Recebido: 29/12/2020 | Revisado: 30/12/2020 | Aceito: 02/01/2021 | Publicado: 04/01/2021

\author{
Andressa Cristina Novaes \\ ORCID: https://orcid.org/0000-0002-9298-5841 \\ Universidade Estadual de Londrina, Brasil \\ E-mail: andressa.novaes@outlook.com \\ Carla Fernanda Tiroli \\ ORCID: https://orcid.org/0000-0002-0974-9689 \\ Universidade Estadual de Londrina, Brasil \\ E-mail: carla_tiroli@yahoo.com.br \\ Beatriz Queiroz Ribeiro \\ ORCID: https://orcid.org/0000-0002-0603-0804 \\ Universidade Estadual de Londrina, Brasil \\ E-mail: biaqribeiro@gmail.com \\ Natália Marciano de Araujo Ferreira \\ ORCID: https://orcid.org/0000-0002-5802-6188 \\ Universidade Estadual de Londrina, Brasil \\ E-mail: natty_fdj@hotmail.com \\ Rejane Kiyomi Furuya \\ ORCID: https://orcid.org/0000-0003-0885-5364 \\ Instituto Federal do Paraná, Brasil \\ E-mail: re.furuya@gmail.com \\ Ligia Carla Faccin Galhardi \\ ORCID: https://orcid.org/0000-0002-7522-9710 \\ Universidade Estadual de Londrina, Brasil \\ E-mail: lgalhardi@uel.br \\ Danieli Juliani Garbuio Tomedi \\ ORCID: https://orcid.org/0000-0002-5808-1603 \\ Universidade Estadual de Londrina, Brasil \\ E-mail: danieligarbuio@gmail.com \\ Lucas Fraga Cotarelli \\ ORCID: https://orcid.org/0000-0002-9820-6052 \\ Universidade Estadual de Londrina, Brasil \\ E-mail: lucasfragacotarelli@hotmail.com \\ Flávia Meneguetti Pieri \\ ORCID: https://orcid.org/0000-0003-1239-2550 \\ Universidade Estadual de Londrina, Brasil \\ E-mail: fpieri@uel.br
}

\begin{abstract}
Resumo
Introdução: enfrentar as hepatites virais tem sido um grande desafio, principalmente para países que apresentam alta prevalência da doença e vulnerabilidades sociais que dificultam o acesso à atenção. Objetivo: investigar a produção científica nacional sobre as estratégias de prevenção, controle e tratamento acerca das hepatites virais. Metodologia: trata-se de uma revisão integrativa operacionalizada mediante consulta às bases/bibliotecas: Banco de Dados em Enfermagem (BDENF), Literatura Latino-Americana e do Caribe em Ciências da Saúde (LILACS), Scientific Eletronic Library Online (SciELO) e National Library of Medicine National Institutes of Health (PubMed) via MEDLINE, de janeiro de 1998 a dezembro de 2019. A pergunta norteadora foi: No que concerne às HV em seres humanos, quais as estratégias desempenhadas pelos serviços de saúde para o controle, tratamento e prevenção, descritos em estudos quantitativos nacionais publicados no período de janeiro de 1998 a dezembro de 2019? Utilizouse do fluxograma PRISMA para seleção dos artigos. Resultados: foram encontrados 2722 artigos empíricos, 26 deles atenderam aos critérios de seleção e foram agrupados nas seguintes categorias: I. Tratamento - 84,6\% (22); e II. Prevenção e Controle - 15,3\% (4). Nesse âmbito, destaca-se o tratamento da Hepatite C com uso de Interferons com ou sem Ribavirina ( $86,3 \%$ ) e os principais efeitos adversos: cefaleia, anemia e fadiga. Conclusão: evidenciaram-se, na literatura nacional, abordagem maior sobre tratamento, principalmente da Hepatite $\mathrm{C}$, e uma escassez de estudos sobre as estratégias de prevenção e controle das hepatites virais, o que denota a relevância de ampliar as publicações, sistematizando os planos efetivos de intervenção que os serviços de Saúde desempenham.
\end{abstract}

Palavras-chave: Hepatite viral; Estratégias nacionais; Vigilância de doença crônica; Enfermagem; Revisão. 


\begin{abstract}
Introduction: confront with viral hepatitis has been a major challenge, especially for countries with high prevalence and social vulnerabilities that make access to care difficult. Objective: To investigate the national scientific production on strategies for prevention, control and treatment of viral hepatitis. Methodology: it is an integrative review operationalized through consultation with the bases/libraries: Nursing Database (BDENF), Latin American and Caribbean Literature in Health Sciences (LILACS), Scientific Electronic Library Online (SciELO) and National Library of Medicine National Institutes of Health (PubMed) via MEDLINE, from January 1998 to December 2019.The main question was: With regard to HV in humans, what are the strategies performed by health services for control, treatment and prevention, described in national quantitative studies published from January 1998 to December 2019? The PRISMA flowchart was used to select the articles. Results: we found 2722 empirical articles, 26 of which met the selection criteria, and were grouped into the following categories: I. Treatment - 84.6\% (22) and II. Prevention and Control - 15,3\% (4).The treatment of Hepatitis C (86.3\%) with use of Interferons with or without Ribavirin and the main adverse effects are headache, anemia and fatigue. Conclusion: there has been evidence in the national literature of a broader approach to treatment, especially of Hepatitis $\mathrm{C}$, and a lack of studies on prevention and control strategies for viral hepatitis, which denotes the relevance of expanding publications systematizing the effective intervention plans that health services perform.
\end{abstract}

Keywords: Viral hepatitis; National strategies; Chronic disease surveillance; Nursing; Review.

\title{
Resumen
}

Introducción: enfrentar la hepatitis viral ha sido un gran desafío, especialmente para los países que tienen una alta prevalencia de la enfermedad y vulnerabilidades sociales que dificultan el acceso al cuidado. Objetivo: investigar la producción científica nacional sobre estrategias de prevención, control y tratamiento de las hepatitis virales. Metodologia: consiste en una revisión integrante realizada consultando las bases de datos/bibliotecas: Biblioteca Virtual en Salud (BVS), Base de Datos de Enfermería (BDENF), Literatura Latino americana y del Caribe en Ciencias de la Salud (LILACS), Scientific Eletronic Library Online (SciELO) y e la National Library of Medicine National Institutes of Health (PubMed) através de la MEDLINE, de enero de 1998 a diciembre de 2019. La pregunta orientadora fue: Con respecto al HV en humanos, cuales son las estratégias que realizan los servicios de salud para su control, tratamiento y prevención, descritas en los estúdios cuantitativos nacionales publicados desde enero 1998 a diciember de 2019? Para la selección de los artículos se utilizó el diagrama de flujo PRISMA. Resultados: se encontraron 2722 artículos empíricos, 26 de ellos cumplieron con los criterios de selección y fueran clasificados en las siguientes categorías: I. Tratamiento - 84,6\% (22) y II. Prevención y Control - 15,3\% (4). Se destaca el tratamiento de la Hepatitis $\mathrm{C}$ con el uso de Interferones con o sin Ribavirina $(86,3 \%)$ y los principales efectos adversos: cefalea, anemia y fatiga. Conclusión: en la literatura nacional se evidenció un mayor abordaje de tratamiento, sobre todo para la Hepatitis C, y una ausencia de estudios sobre estrategias de prevención y control de la hepatitis viral, lo que indica la relevancia de ampliar las publicaciones mediante la sistematización de los planes de intervención efectivos que los servicios de salud cumplen.

Palabras clave: Hepatitis viral; Estrategias nacionales; Vigilancia de enfermedad crónica; Enfermería; Revisión.

\section{Introdução}

A preocupação em relação às Hepatites Virais (HV) e a mobilização para a luta contra elas são mundiais. A estratégia global do setor Saúde para HV, da Organização Mundial da Saúde (OMS), endossada pelo Brasil, adota iniciativas voltadas à prevenção e ao controle desse agravo, para atingir os objetivos na agenda até 2030 (WHO, 2019).

O intuito é reduzir em $90 \%$ as novas infecções por HV e em $65 \%$ as mortes, no período de 2016 a 2030 . A estratégia aborda todos os vírus da hepatite (A, B, C, D e E), com um foco particular nas Hepatites B e C, pertencentes às famílias Hepadnaviridae e Flaviviridade, devido às características epidemiológicas, potencial para complicações e à carga relativa de saúde pública que representam (WHO, 2019; Timóteo et al, 2020, Oliveira et al., 2020).

As HV são a segunda maior causa de morte entre as doenças infecciosas, depois da tuberculose. Salienta-se que estas doenças são negligenciadas e estão diretamente ligadas ao nível socioeconômico de cada região. No mais, nove vezes mais pessoas são infectadas com hepatite que com o Vírus da Imunodeficiência Humana (HIV - Human Immunodeficiency Virus). A hepatite é evitável, tratável e, no caso da Hepatite C, as chances de remissão da infecção são significativas (Brasil, 2019; Sousa, Farias, Macedo \& Farias, 2020). 
De 1999 a 2018, foram notificados no Sistema de Informação de Agravos de Notificação (SINAN) 632.814 casos confirmados de HV no Brasil. Desses, 167.108 (26,4\%) são referentes aos casos de Hepatite A; 233.027 (36,8\%), aos de Hepatite B; 228.695 (36,1\%), aos de Hepatite C; e 3.984 (0,7\%), aos de Hepatite D (ou Delta) (Brasil, 2019).

Nesse sentido, o Ministério da Saúde (MS) vem desenvolvendo ações focadas em ampliar o acesso, bem como incrementar a qualidade e a capacidade instalada dos serviços de Saúde. Entretanto, as principais populações-chave ainda não estão sendo adequadamente alcançadas por medidas de prevenção, testagem, tratamento e cuidados de forma integral (Brasil, 2016; Almeida et al., 2019).

Nessa perspectiva e partindo-se da premissa de que existem múltiplos fatores para a ocorrência das HV no Brasil, torna-se necessário elucidar de que maneira esses movimentos têm sido suficientemente abordados e investigados.

A partir do exposto, objetivou-se apresentar uma revisão integrativa com o intuito de investigar a produção científica nacional sobre as estratégias de prevenção, controle e tratamento das HV.

\section{Metodologia}

Trata-se de uma revisão integrativa da literatura por meio de busca sistemática de artigos, de natureza qualitativa, com propósito de sintetizar os principais resultados dos estudos nacionais produzidos acerca das $\mathrm{HV}$ em seres humanos em prol da prevenção, do controle e do tratamento, cuja análise é de caráter exploratório (Mendes, Silveira, \& Galvão, 2008; Sousa, Marques-Vieira, Severino, Antunes, 2017; Pereira, Shitsuka, Parreira \& Shitsuka, 2020). A revisão foi composta por seis etapas (Souza, Silva, \& Carvalho, 2010): elaboração da pergunta norteadora; busca ou amostragem na literatura; coleta de dados; análise crítica dos estudos incluídos; discussão dos resultados; apresentação da revisão integrativa.

Esta pesquisa seguiu a recomendação PRISMA-P (Principais Itens para Relatar Revisões Sistemáticas e MetaAnálises) (Moher, Liberati, Tetzlaff, \& Altman, 2015). A estratégia PICOS, que representa um acrônimo para Paciente, Intervenção, Comparação, Outcomes e Tipos de Estudos (Study Design), foi empregada para a construção da pergunta de pesquisa (Santos, Pimenta, \& Nobre, 2007).

Desse modo, foi definida a seguinte pergunta norteadora, utilizando a estratégia PICOS: no que concerne às HV em seres humanos, quais as estratégias desempenhadas pelos serviços de saúde para o controle, tratamento e prevenção, descritos em estudos quantitativos nacionais publicados no período de janeiro de 1998 a dezembro de 2019? A saber, levando em conta PICOS, P representa seres humanos com Hepatites Virais; I, estratégias desempenhadas pelos serviços de Saúde; C, não houve comparação; O, controle, tratamento e prevenção; S, estudos nacionais quantitativos.

Salienta-se que a pergunta norteadora foi elaborada de forma ampla pois seriam inclusas todas as estratégias apresentadas e descritas nos estudos, realizadas nos serviços de Saúde por um profissional da área.

O recorte temporal foi determinado pelo fato de o ano de 1998 ser considerado um marco histórico, quando foi instituída a vacina contra Hepatite B, que passou a ser produzida no Brasil e aplicada em crianças menores de um ano em todos os municípios (Brasil, 2013).

Utilizaram-se como critérios de inclusão os artigos com método quantitativo, nacionais, nos idiomas português, inglês ou espanhol, disponibilizados na íntegra e publicados nos últimos vinte e um anos (de janeiro de 1998 a dezembro de 2019), com acesso livre, temática pertinente ao objetivo da revisão integrativa e que contribuíssem para responder à questão norteadora.

Foram excluídos os protocolos de pesquisa, teses, dissertações, carta editorial, trabalho de conclusão de curso (TCC), resenhas e relatórios, revisão e capítulo de livros, erratas e comentários de artigos, duplicidades, artigos indisponíveis 
gratuitamente na íntegra ou por meio de conta institucional, obituários, documentos não oficiais, pesquisa que abordasse somente mutação genética do vírus e estudos qualitativos.

As bases de dados eletrônicas selecionadas foram: Banco de Dados em Enfermagem (BDENF), Literatura LatinoAmericana e do Caribe em Ciências da Saúde (LILACS), Scientific Eletronic Library Online (SciELO) e National Library of Medicine National Institutes of Health (PubMed) via MEDLINE. Nas buscas pelos manuscritos, foram utilizados os Descritores em Ciências da Saúde (DeCS) e seus correspondentes na língua inglesa que compõem o Medical Subject Headings (MeSH), além de descritores em espanhol:

(P) - português: Hepatite Viral Humana; Hepatites Virais Humanas; Hepatite Viral;i nglês: Hepatitis; Viral; Human; e espanhol: Hepatites Viral Humana.

(I) - português: Estratégias de eSaúde; Diretrizes para Supervisão e Avaliação da eSaúde Nacional; Estratégias Nacionais; Estratégia de eSaúde; Estratégia da eSaúde da OMS; Estratégias e Políticas de eSaúde; Monitorização e Avaliação da Saúde Nacional; Plano de Ação sobre eSaúde; Plano de Ação para a Saúde a Nível Nacional; Programas e Iniciativas voltados a eSaúde; Recomendações Estratégicas para a Saúde Nacional;inglês: National Strategies; eHealth Strategies; e espanhol: Estratégias Nacionales; Estrategias de Salud.

(O) - português: Adesão à medicação; Aderência ao Tratamento Medicamentoso; Adesão ao Medicamento; Não Aderência ao Medicamento; Não Adesão ao Medicamento; Imunidade; Cobertura Vacinal; Cobertura de Imunização; Cobertura de Vacinação; Coberturas Vacinais; Coberturas de Imunização; Cobertura do Programa Ampliado de Imunizações; Taxa de Vacinação; Morte; Óbito; Doença Sexualmente Transmissível; DST; DSTs; Infecções Sexualmente Transmissíveis; IST; Casos Crônicos; Doenças Crônicas; Moléstia Crônica; Quadros Crônicos; Indicador de Doença Crônica; Vigilância de Doença Crônica; Doença Degenerativa; Transmissão da Mãe para a Criança; Transmissão da Mãe para o Recém-Nascido; Transmissão Vertical; Transmissão de Doença Infecciosa; Transmissão; Doenças Virais Sexualmente Transmissíveis; Doenças Virais de Transmissão Sexual; Doenças Virais Sexualmente Transmitidas; inglês: Medication Adherence; Immunity; Vaccination Coverage; Death; Sexually Transmitted Diseases; Chronic Disease; Chronic Disease Indicators; Infectious Disease Transmission;Vertical; DiseaseTransmission, Infectious; SexuallyTransmittedDeseases, Viral; eespanhol: Cumplimiento de laMedicación;Inmunidad; Cobertura de Vacunación; Muerte; Enfermedades de Transmisión Sexual; Enfermedad Crónica; Indicadores de Enfermedades Crónicas; Transmisión Vertical de Enfermedad Infecciosa; Transmisión de Enfermedad Infecciosa; Enfermedades Virales de Transmisión Sexual.

(S) - português: Análise Transversal; Estudos de Casos e Controles; Apresentação de Caso; Estudo de Caso; Estudo Observacional; inglês: Demography; Case-Control Studies; Case Reports; Observational Study; e espanhol: Demografía; Estudios de Casos y Controles; Informes de Casos; Estudio Observacional.

Todos os descritores foram combinados entre si por meio dos operadores booleanos AND, OR e NOT.

Ademais, a busca ou amostragem na literatura em cada base de dados foi realizada pela pesquisadora principal e ocorreu em março de 2020. Foi encontrado um total de 2722 artigos. Para o total de artigos selecionados foram aplicadas três etapas de identificação e seleção: identificação dos artigos nas bases de dados; seleção dos artigos por meio da leitura dos títulos e resumos; e elegibilidade dos artigos de acordo com a pergunta de pesquisa.

Para a seleção dos artigos, quatro pesquisadores independentes avaliaram os estudos previamente identificados. Nos casos em que um consenso não foi obtido, um quinto examinador foi consultado e, com base no seu parecer, prestado sem conhecimento prévio dos exames já feitos, decidiu-se pela inclusão ou não do manuscrito.

A extração das informações dos artigos selecionados para a leitura dos textos completos foi realizada mediante utilização de um formulário elaborado segundo as recomendações propostas por Galvão (2006). Os itens considerados essenciais para responder à questão norteadora da revisão foram: identificação do artigo (autor, ano de publicação, periódico, 
qualis da enfermagem/quadriênio, base de dados); (período e local de estudo; título; tipo de estudo; amostra; critérios de inclusão e exclusão); (classificação da HV; estratégia de tratamento, incluindo conclusão e efeitos adversos); (estratégias de prevenção, controle e recomendações).

Todos os títulos e resumos inicialmente selecionados foram exportados de cada base de dados para o programa Endnote versão 9 (Thomson, Reuters, Carlsbad, Usa), a fim de se fazer a análise. Posteriormente, ainda nessa etapa, usou-se o Software State of the Art through Systematic Review (StArt®), uma ferramenta desenvolvida pelo Laboratório de Pesquisa de Engenharia de Software do Departamento de Computação da Universidade Federal de São Carlos (Fabbri et al., 2016).

Com os resultados sintetizados e agrupados em três quadros sinópticos, procedeu-se com a análise criteriosa, detalhada e descritiva, confrontando os dados com o conhecimento teórico, em busca de integralização dos resultados (Whittemore \& Knafl, 2005).

Por fim, realizou-se uma análise crítica dos estudos de modo a conhecer o enfoque da produção científica nacional sobre as estratégias de prevenção, controle e tratamento acerca das HV em seres humanos. Essa etapa seguiu os seguintes passos metodológicos: identificação do problema de estudo; levantamento da literatura; avaliação crítica dos estudos; e análise dos dados, os quais forneceram uma organização metodológica e um rigor ao estudo.

Após a conclusão da análise, foi realizada uma síntese dos elementos importantes, de maneira a retratar a temática, apresentando-os em quadros. A interpretação dos dados ocorreu de forma crítica e imparcial, a fim de permitir apresentações de possíveis explicações para os resultados encontrados, fossem eles convergentes ou conflitantes, com base na literatura disponível.

\section{Resultados}

Foi encontrado um total de 2722 artigos e, após as etapas de seleção mediante leitura do título e, posteriormente, do resumo (Figura 1), selecionaram-se 26 artigos para compor esta revisão, os quais foram submetidos à leitura na íntegra. 
Figura 1 - Fluxograma do processo de identificação e seleção dos artigos.

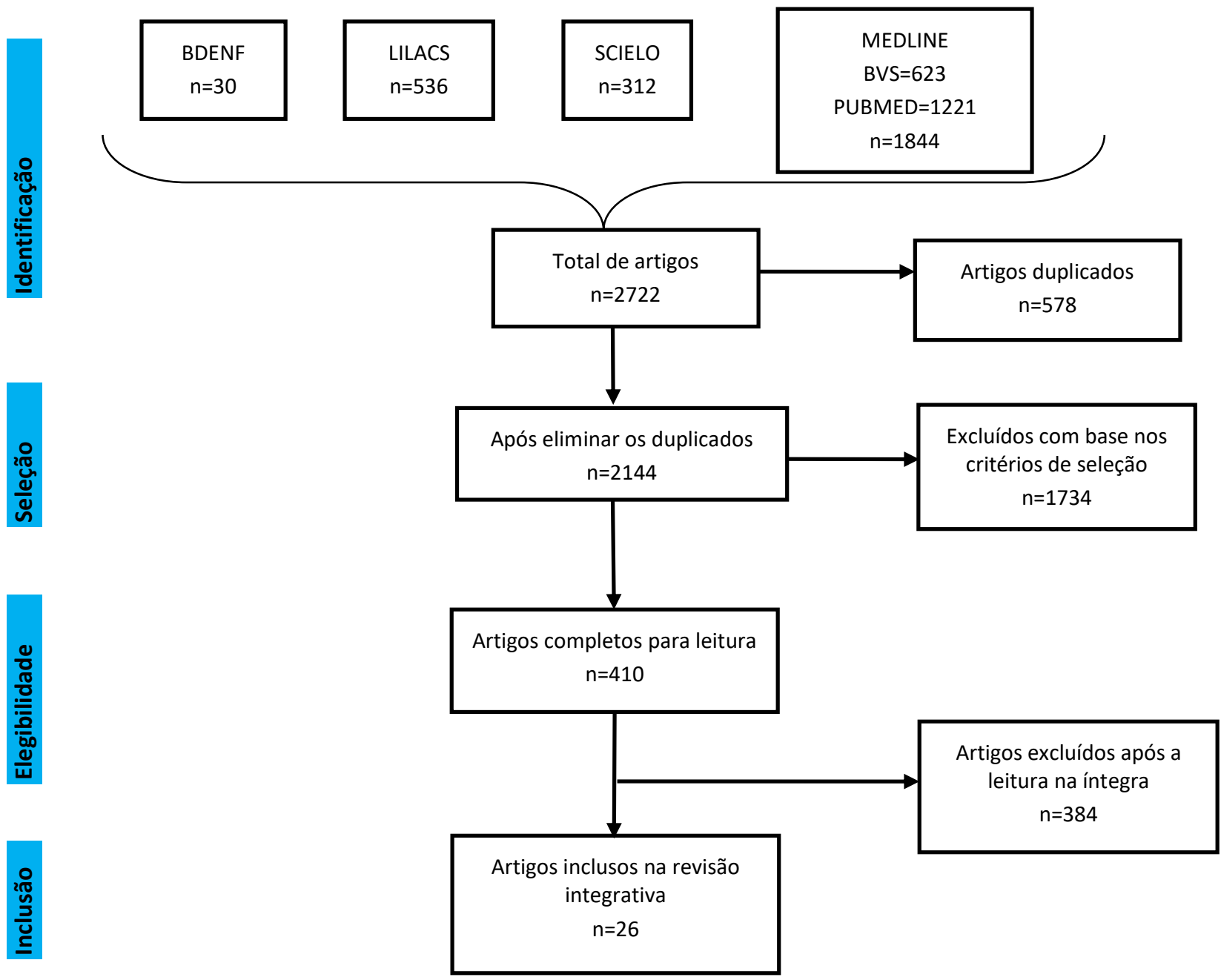

Fonte: adaptado do diagrama PRISMA-P 2015 Statement (Liberatiet al., 2009).

Observa-se na análise da Figura 1 que dos 2722 artigos encontrados 578 foram excluídos por duplicidade e que após as etapas de seleção e elegibilidade excluíram-se 2118 estudos, totalizando uma amostra de 26 artigos.

Os dados obtidos foram organizados em três quadros, que contemplam as principais informações dos estudos selecionados nesta revisão integrativa. O Quadro 1 apresenta as características dos artigos selecionados na revisão integrativa.

A amostra desta revisão foi composta por 26 artigos primários, sendo o maior número de publicações pertencentes ao quadriênio 2010-2013 (46,1\%), seguido do quadriênio 2014-2018 (38,4\%). No quadriênio 2002-2005, houve apenas uma publicação $(3,8 \%)$ e, no quadriênio 2006-2009, houve duas publicações (7,6\%). Em 2019, houve apenas uma publicação referente a essa temática (3,8\%). Ressalta-se que, no quadriênio 1998-2001, não houve estudos inclusos nesta revisão.

Foi evidenciada uma maior concentração de estudos nas regiões sul $(26,9 \%)$ e sudeste $(23,0 \%)$. Em contrapartida, as demais regiões obtiveram um pequeno contingente de estudos centro-oeste $(11,5 \%)$, nordeste $(7,6 \%)$ e norte $(3,8 \%)$. Destacase a pequena quantidade de estudos multicêntricos $(26,9 \%)$.

Quanto aos periódicos, destacaram-se aqueles específicos de hepatologia $(n=6)$ e gastroenterologia $(n=3)$, doenças infecciosas $(n=6)$ e medicina tropical $(n=4)$, com qualis entre A1 e B3. Nesse particular, é oportuno evidenciar a participação de enfermeiros em $50 \%$ publicações. 
Quanto ao delineamento da pesquisa, evidenciou-se grande quantidade de estudos observacionais, sendo 53,8\% coorte e $30,7 \%$ transversal. Vale salientar que houve apenas quatro estudos de intervenção, viabilizados por ensaios clínicos randomizados $(15,3 \%)$.

Quadro 1 - Síntese geral dos estudos elegidos na revisão integrativa segundo autores, ano/local da pesquisa, periódico, qualis/ enfermagem, base de dados, título do artigo, tipo de estudo, período de análise, tamanho da amostra e critérios de inclusãoBrasil (janeiro de 1998 a dezembro de 2019).

\begin{tabular}{|c|c|c|}
\hline ID & $\begin{array}{c}\text { Autores/Ano/Local/ Periódico/ } \\
\text { Qualis Da ENFERMAGEM/BaSe De DAdos/ } \\
\text { Título do ARTigo }\end{array}$ & $\begin{array}{l}\text { TIPO DE ESTUDO/PERÍODO DE ANÁLISE/TAMANHO DA } \\
\text { AMOSTRA/CRITÉRIOS DE INCLUSÃo }\end{array}$ \\
\hline E1 & $\begin{array}{l}\text { Acras, R. N. et al.; 2004; Curitiba (PR); Arquivos } \\
\text { de Gastroenterologia; B2; SciELO. } \\
\text { A taxa de resposta sustentada da Hepatite C } \\
\text { crônica ao tratamento com os diversos } \\
\text { Interferons-alfa e Ribavirinas distribuídos pelo } \\
\text { governo brasileiro é semelhante à da literatura } \\
\text { mundial. }\end{array}$ & $\begin{array}{l}\text { Tipo de Estudo: coorte, não-controlado. } \\
\text { Período de análise: ago/1999 a ago/2002. } \\
\text { Amostra: } 87 \text { portadores de Hepatite C crônica. } \\
\text { Critérios de inclusão:1) positividade pré-tratamento em, pelo } \\
\text { menos, dois testes anti-VHC (ELISA) de segunda ou terceira } \\
\text { geração e determinação qualitativa do RNA do VHC (VHC- } \\
\text { RNA) através do método da reação em cadeia da polimerase } \\
\text { (PCR); } \\
\text { 2) elevação da alanina aminotransferase (ALT) de } 1,5 \text { x o } \\
\text { limite superior de normalidade, por duas oportunidades, em } 6 \\
\text { meses; } \\
\text { 3) biopsia hepática nos últimos } 12 \text { meses, evidenciando } \\
\text { atividade necroinflamatória de moderada a intensa e/ou fibrose. } \\
\text { Foram dispensados da biopsia somente os casos que } \\
\text { apresentavam algum distúrbio hereditário de coagulação. }\end{array}$ \\
\hline E2 & $\begin{array}{l}\text { Oliveira, M. D. S. O. et al.; 2006; Região } \\
\text { metropolitana de Goiânia (GO); Memórias do } \\
\text { Instituto Oswaldo Cruz; A2; SciELO. } \\
\text { Seroepidemiology of hepatitis B virus infection } \\
\text { and high rate of response to hepatitis B virus } \\
\text { Butang® vaccine in adolescents from low income } \\
\text { families in Central Brazil. }\end{array}$ & $\begin{array}{l}\text { Tipo de Estudo: coorte. } \\
\text { Período de análise: nov/2003 a nov/2004. } \\
\text { Amostra: } 664 \text { adolescentes. } \\
\text { Critérios de inclusão: } 664 \text { indivíduos (entre } 12 \text { e } 19 \text { anos) } \\
\text { matriculados em novembro de } 2003 \text { na Escola A ena escola B. }\end{array}$ \\
\hline E3 & $\begin{array}{l}\text { Motta-Castro, A. R. C. et al.; 2009; Comunidades } \\
\text { remanescentes de quilombos - MS; Cadernos de } \\
\text { Saúde Pública; A2; SciELO. } \\
\text { Compliance with and response to hepatitis B } \\
\text { vaccination in remaining quilombo communities } \\
\text { in Central Brazil. }\end{array}$ & $\begin{array}{l}\text { Tipo de estudo: coorte. } \\
\text { Período de análise: } 2003 \text {. } \\
\text { Amostra: } 708 \text { moradores de quilombos. } \\
\text { Critérios de inclusão: foram convidados a participar do } \\
\text { programa de vacinação contra a Hepatite B os moradores de } \\
\text { oito comunidades remanescentes de quilombos no Mato Grosso } \\
\text { do Sul. }\end{array}$ \\
\hline E4 & $\begin{array}{l}\text { Ferreira, S. da C. et al.; 2010; Ribeirão Preto } \\
\text { (SP); The Brazilian Journal of Infectous } \\
\text { Diseases; B1; SciELO. } \\
\text { Long-term follow-up of patients with chronic } \\
\text { hepatitis C with sustained virologic response to } \\
\text { Interferon. }\end{array}$ & $\begin{array}{l}\text { Tipo de estudo: coorte. } \\
\text { Período de análise: } 1994 \text { a } 2007 . \\
\text { Amostra: } 174 \text { portadores de HCV crônica. } \\
\text { Critérios de inclusão: } 174 \text { pacientes conhecidos por } \\
\text { desenvolverem RVS após terapia com diferentes formas de } \\
\text { monoterapia com IFN ou IFN combinada com a RBV. }\end{array}$ \\
\hline E5 & $\begin{array}{l}\text { Gonçales JR., F. L. et al.; 2010; Campinas (SP); } \\
\text { BMC Infectious Diseases; A1; PubMed. } \\
\text { Research article Retreatment of hepatitis C } \\
\text { patients with pegylated Interferon combined with } \\
\text { Ribavirin in non-responders to Interferon plus } \\
\text { Ribavirin. Is it different in real life? }\end{array}$ & $\begin{array}{l}\text { Tipo de estudo: coorte retrospectiva. } \\
\text { Período de análise: } 2005 \text { a } 2007 . \\
\text { Amostra: } 130 \text { pacientes crônicos de HCV. } \\
\text { Critérios de inclusão: indivíduos não respondedores à terapia } \\
\text { com Interferon mais Ribavirina e que aceitaram o retratamento }\end{array}$ \\
\hline
\end{tabular}




\begin{tabular}{|c|c|c|}
\hline & & com Peguinterferon mais Ribavirina. \\
\hline E6 & $\begin{array}{l}\text { Lérias de Almeida, P. R. et al.; 2010; Porto } \\
\text { Alegre (RS); Annals of Hepatology; B1; } \\
\text { PubMed. } \\
\text { Sustained virological reponse according to the } \\
\text { type of early virological reponse in HCV and } \\
\text { HCV/HIV }\end{array}$ & $\begin{array}{l}\text { Tipo de estudo: coorte retrospectiva. } \\
\text { Período de análise: não informado. } \\
\text { Amostra: } 323 \mathrm{HCV} \text { mono-infectados, } 59 \mathrm{HCV} / \mathrm{HIV} \\
\text { coinfectados, genótipo } 1 . \\
\text { Critérios de inclusão: indivíduos com PCR-HCV } \\
\text { positivo; genótipo 1; aminotransferases elevadas; biópsia com } \\
\text { fibrose septal (maior ou igual aF2, de acordo com o escore } \\
\text { METAVIR); entre } 18 \mathrm{e} 70 \text { anos; com contagem de plaquetas } \\
\text { superior a } 75.000 / \mathrm{mm} 3 \text { para cirróticos e } 90.000 / \mathrm{mm} 3 \text { para não } \\
\text { cirróticos e uma contagem de neutrófilos superior a } 1.500 / \\
\text { mm3. }\end{array}$ \\
\hline E7 & $\begin{array}{l}\text { Narciso-Schiavon, J. L. et al.; 2010; São Paulo } \\
\text { (SP); Revista da Sociedade Brasileira de } \\
\text { Medicina Tropical; B1; SciELO. } \\
\text { Gender influence on treatment of chronic } \\
\text { hepatitis C genotype } 1\end{array}$ & $\begin{array}{l}\text { Tipo de estudo: coorte retrospectiva. } \\
\text { Período de análise: jan/2001 e dez/ } 2007 . \\
\text { Amostra: } 181 \text { portadores crônicos do HCV, genótipo 1, em } \\
\text { tratamento com Peg-Interferon e Ribavirina. } \\
\text { Critérios de inclusão: pacientes adultos com Hepatite C } \\
\text { crônica, comprovada por biópsia, genótipo } 1 \text { e que foram } \\
\text { tratados com Peg-IFN e RBV entre janeiro de } 2001 \text { e dezembro } \\
\text { de } 2007 \text {. }\end{array}$ \\
\hline E8 & $\begin{array}{l}\text { Gardenal, R. V. C. et al.; 2011; Campo Grande } \\
\text { (MS); Revista da Sociedade Brasileira de } \\
\text { Medicina Tropical; B1; SciELO. } \\
\text { Hepatite C e gestação: análise de fatores } \\
\text { associados à transmissão vertical }\end{array}$ & $\begin{array}{l}\text { Tipo de estudo: transversal. } \\
\text { Período de análise: } 2002 \text { a } 2005 . \\
\text { Amostra: } 23 \text { gestantes com infecção pelo HCV. } \\
\text { Critérios de inclusão: gestantes cadastradas no Sistema de } \\
\text { Informação do Programa de Humanização no Pré-natale } \\
\text { Nascimento (SISPRENATAL), triadas pelo Programa de } \\
\text { Proteção à Gestante (PPG) e que apresentaram sorologia } \\
\text { reagente e confirmada para VHC no período de } 2002 \text { a } 2005 .\end{array}$ \\
\hline E9 & $\begin{array}{l}\text { Carvalho, P. et al.; 2012; Bahia; Annals of } \\
\text { Hepatology; B1; PubMed. } \\
\text { Hepatitis B virus prevalence and vaccination } \\
\text { response in health care workers and students at } \\
\text { the Federal University of Bahia, Brazil }\end{array}$ & $\begin{array}{l}\text { Tipo de estudo: transversal. } \\
\text { Período de análise: } 2007 . \\
\text { Amostra: } 766 \text { voluntários. } \\
\text { Critérios de inclusão: estudantes de graduação (Medicina, } \\
\text { Enfermagem, Farmácia, Fonoaudiologia, Odontologia, } \\
\text { Biologia e Nutrição) e profissionais da Saúde dos respectivos } \\
\text { cursos da UFBA. }\end{array}$ \\
\hline E10 & $\begin{array}{l}\text { Gonçalves, C. B. T. et al.; 2012; Porto Alegre } \\
\text { (RS); Arquivos de Gastroenterologia; B1; } \\
\text { SciELO. } \\
\text { Effectiveness of alpha Interferon (+ Ribavirin) in } \\
\text { the treatment of chronic viral hepatitis c } \\
\text { genotypes } 2 \text { and } 3 \text { in a brazilian sample }\end{array}$ & $\begin{array}{l}\text { Tipo de estudo: coorte. } \\
\text { Período de análise: ago/2007 a mar/ } 2008 \text {. } \\
\text { Amostra: } 141 \text { pacientes portadores de HCV. } \\
\text { Critérios de inclusão: pacientes que iniciaram o tratamento no } \\
\text { Centro de Aplicação e Monitoramento de Medicamentos } \\
\text { Injetáveis (CAMMI), de agosto de } 2007 \text { a março de } 2008 \text {. }\end{array}$ \\
\hline E11 & $\begin{array}{l}\text { Lobato, C. M. O. et al.; 2012; Rio Branco (AC), } \\
\text { Fortaleza (CE), Niterói (RJ), Vitória (ES) e } \\
\text { Cuiabá (MT); Revista da Sociedade Brasileira de } \\
\text { Medicina Tropical; B1; SciELO } \\
\text { Effectiveness of first-wave protease inhibitors in } \\
\text { hepatitis C virus genotype } 1 \text { infection: a } \\
\text { multicenter study in Brazil }\end{array}$ & $\begin{array}{l}\text { Tipo de estudo: coorte. } \\
\text { Período de análise: } 2013 \text { a } 2014 \text {. } \\
\text { Amostra: } 275 \text { portadores de HCV em estágios avançados de } \\
\text { fibrose. } \\
\text { Critérios de inclusão: pacientes com fibrose de fígado } \\
\text { avançada (F3 ou F4). Pacientes com fibrose moderada } \\
\text { (METAVIR, F2), confirmada por biópsia hepática realizada há } \\
\text { mais de } 3 \text { anos, além de pacientes com graves manifestações } \\
\text { extra-hepáticas, independentemente do grau de fibrose. } \\
\text { Disponível para pacientes virgens de tratamento e aqueles que } \\
\text { não conseguiram atingir a RVS em tratamentos anteriores. }\end{array}$ \\
\hline E12 & $\begin{array}{l}\text { Mello, F. C. do A. et al.; 2012; Espírito Santo, } \\
\text { Minas Geraise Santa Catarina; Memórias do }\end{array}$ & $\begin{array}{l}\text { Tipo de estudo: transversal. } \\
\text { Período de análise: } 2008 \text { a } 2009 .\end{array}$ \\
\hline
\end{tabular}




\begin{tabular}{|c|c|c|}
\hline & $\begin{array}{l}\text { Instituto Oswaldo Cruz; A2; SciELO. } \\
\text { Antiviral therapy against chronic hepatitis B in } \\
\text { Brazil: high rates of Lamivudine resistance } \\
\text { mutations and correlation with HBV genotypes }\end{array}$ & $\begin{array}{l}\text { Amostra: } 129 \text { portadores crônicos de HBV. } \\
\text { Critérios de inclusão: amostras positivas de soro HBsAg } \\
\text { coletadas entre } 2008-2009 \text { de pacientes HBV cronicamente } \\
\text { infectados e submetidos a diferentes terapias medicamentosas. }\end{array}$ \\
\hline E13 & $\begin{array}{l}\text { Pêssoa, M. G. et al.; 2012; Multicêntrico (não } \\
\text { informa o local); Annals of Hepatology; B1; } \\
\text { PubMed. } \\
\text { Re-treatment of previous non-responders and } \\
\text { relapsers to Interferon plus Ribavirin with Peg- } \\
\text { Interferon alfa-2a (40KD), Ribavirin } \pm \\
\text { amantadine in patients with chronic hepatitis C: } \\
\text { randomized multicentre clinical trial }\end{array}$ & $\begin{array}{l}\text { Tipo de estudo: ensaio clínico randomizado. } \\
\text { Período de análise: jul/2003 a nov/2005. } \\
\text { Amostra: } 186 \text { portadores crônicos do HCV: } 106 \text { não } \\
\text { respondedor e se } 80 \text { recidivantes. } \\
\text { Critérios de inclusão: adultos com anti-HCV positivo, RNA- } \\
\text { HCV detectável, alanina aminotransferase elevada, níveis } \\
\text { séricos de transaminase (ALT) elevados em pelo menos duas } \\
\text { ocasiões durante os } 6 \text { meses, com resultado de biópsia nos } 36 \\
\text { meses anteriores com indício de CHC e pacientes com cirrose } \\
\text { hepática não descompensada (classe A de Child-Pugh). }\end{array}$ \\
\hline E14 & $\begin{array}{l}\text { Espírito Santo, M. P. do et al.; 2013; Rio de } \\
\text { Janeiro (RJ); Annals of Hepatology; B2; } \\
\text { PubMed. } \\
\text { Analysis of hepatitis C virus (HCV) RNA load in } \\
\text { platelets of HCV-monoinfected patients receiving } \\
\text { antiviral therapy }\end{array}$ & $\begin{array}{l}\text { Tipo de estudo: coorte. } \\
\text { Período de análise: } \operatorname{mar} / 2010 \text { a ago/2011. } \\
\text { Amostra: } 17 \text { pacientes. } \\
\text { Critérios de inclusão: pacientes monoinfectados cronicamente } \\
\text { pelo HCV, genótipo } 1 .\end{array}$ \\
\hline E15 & $\begin{array}{l}\text { Silva, I. et al.; 2013; São Paulo (SP) } \\
\text { (Ambulatório de Hepatite da Universidade } \\
\text { Federal de São Paulo).; Annals of Hepatology; } \\
\text { B2; PubMed. } \\
\text { Poor response to hepatitis C treatment in elderly } \\
\text { patients }\end{array}$ & $\begin{array}{l}\text { Tipo de estudo: transversal. } \\
\text { Período de análise: } 2005 \text { a } 2010 . \\
\text { Amostra: } 231 \text { pacientes idosos. } \\
\text { Critérios de inclusão: idosos infectados com o genótipo } 1 \text { e } \\
\text { tratados com Peg-IFN e RBV. }\end{array}$ \\
\hline E16 & $\begin{array}{l}\text { Garcia, J. H. P. et al.; 2015; Fortaleza (CE) } \\
\text { (Hospital Universitário Walter Cantídio); } \\
\text { Arquivos de Gastroenterologia; B1; SciELO. } \\
\text { Pegylated Interferon and Ribavirin for treatment } \\
\text { of recurrent hepatitis c after liver transplantation: } \\
\text { a single-liver transplant center experience in } \\
\text { brazil. }\end{array}$ & $\begin{array}{l}\text { Tipo de estudo: coorte observacional, descritivo e analítico. } \\
\text { Período de análise: mai/2002 a dez/2011. } \\
\text { Amostra: } 601 \text { pacientes que realizaram transplante hepático. } \\
\text { Critérios de inclusão: elegíveis para tratamento se positivos } \\
\text { para RNA do HCV sérico e se a recorrência (estágio de fibrose } \\
\geq 1 \text { ou grau de atividade } \geq 2 \text { ) fosse detectada na histologia. }\end{array}$ \\
\hline E17 & $\begin{array}{l}\text { Borzacov, L. M. P. et al.; 2016; Rondônia (RO); } \\
\text { International Journal of Infectious Diseases; B1; } \\
\text { PubMed. } \\
\text { Treatment of hepatitis delta virus genotype } 3 \\
\text { infection with Peg-Interferon and Entecavir. }\end{array}$ & $\begin{array}{l}\text { Tipo de estudo: coorte prospectiva não randomizada. } \\
\text { Período de análise: jul/2011 a jul/2012. } \\
\text { Amostra: } 22 \text { indivíduos tratados simultaneamente para HBV e } \\
\text { HDV. } \\
\text { Critérios de inclusão: (1) idade>18 e <70 anos, (2) } \\
\text { diagnóstico sorológico de infecção por HBV e HDV, (3) PCR } \\
\text { positivo para material genético de HDV, (4) nenhuma terapia } \\
\text { antiviral usada nos últimos } 6 \text { meses, (5) o paciente teve que } \\
\text { apresentar uma elevação flutuante ou persistente da alanina } \\
\text { aminotransferase (ALT) em pelo menos duas ocasiões nos } 3 \\
\text { meses anteriores ao início do tratamento, (6) o paciente teve } \\
\text { que apresentar fígado compensado, doença classificada como } \\
\text { Child - Pugh A < } 7 \text { pontos ou MELD <12, (7) o paciente } \\
\text { deveria ser negativo para carcinoma hepatocelular, e (8) o } \\
\text { paciente deveria apresentar critérios laboratoriais que } \\
\text { permitissem o uso do PEG-IFN. }\end{array}$ \\
\hline
\end{tabular}




\begin{tabular}{|c|c|c|}
\hline E18 & $\begin{array}{l}\text { Pereira, C. V. et al.; 2016; sul do Brasil; } \\
\text { Memórias do Instituto Oswaldo Cruz; A2; } \\
\text { SciELO. } \\
\text { Efficacy of Entecavir and Tenofovir in chronic } \\
\text { hepatitis B under treatment in the public health } \\
\text { system in southern Brazil }\end{array}$ & $\begin{array}{l}\text { Tipo de estudo: transversal. } \\
\text { Período de análise: } 2011 \text { a } 2014 \text {. } \\
\text { Amostra: } 640 \text { portadores de HBV. } \\
\text { Critérios de inclusão: todos os pacientes com Hepatite B } \\
\text { crônica em tratamento na rede pública de saúde no sul do } \\
\text { Brasil, maiores de } 18 \text { anos, apresentando dados para pelo } \\
\text { menos uma reavaliação do tratamento em seu prontuário de } \\
\text { acordo com o MS (2009). Dados relativos ao } 1^{\circ} \text { tratamento } \\
\text { realizado com ETV ou TDF em pacientes que não receberam a } \\
\text { terapia foi considerada. }\end{array}$ \\
\hline E19 & $\begin{array}{l}\text { Schacher, F. C et al.; 2016; Porto Alegre (RS) } \\
\text { (Hospital das Clínicas); Clinical \& Biomedical } \\
\text { Research; B3; LILACS. } \\
\text { Resultados da terapia dupla (Interferon e } \\
\text { Ribavirina) para Hepatite C em um centro de } \\
\text { referência no sul do Brasil: um estudo da vida } \\
\text { real. }\end{array}$ & $\begin{array}{l}\text { Tipo de estudo: coorte retrospectivo. } \\
\text { Período de análise: ago/2011 a ago/2014. } \\
\text { Amostra: } 237 \text { pacientes. } \\
\text { Critérios de inclusão: pacientes com infecção crônica pelo } \\
\text { HCV que receberam terapia dupla (associação de RBV com } \\
\text { IFN ou PEG-IFN). }\end{array}$ \\
\hline E20 & $\begin{array}{l}\text { Callefi, L. A. et al.; 2017; Brasil (multicêntrico)- } \\
15 \text { centros de referência; Clinics; A3; SciELO. } \\
\text { Effectiveness and safety of first-generation } \\
\text { protease inhibitors in real-world patients with } \\
\text { hepatitis C virus genotype } 1 \text { infection in Brazil: a } \\
\text { multicenter study. }\end{array}$ & $\begin{array}{l}\text { Tipo de estudo: transversal multicêntrico ( } 15 \text { centros de } \\
\text { referência). } \\
\text { Período de análise: jul/2013 a abr/2014. } \\
\text { Amostra: } 715 \text { pacientes. } \\
\text { Critérios de inclusão: pacientes cronicamente monoinfectados } \\
\text { com o genótipo } 1 \text { do HCV (virgens de tratamento ou } \\
\text { previamente tratados com Peg-IFN e RBV) que foram tratados } \\
\text { com Peg-IFN ( } \alpha 2 \mathrm{a} \text { ou } \alpha 2 \mathrm{~b}), \text { RBV e BOC ou TVR. }\end{array}$ \\
\hline E21 & $\begin{array}{l}\text { Grando, A. V. et al.; 2017; São Paulo (SP), } \\
\text { Ribeirão Preto (SP), Rio de Janeiro (RJ), Espírito } \\
\text { Santo (ES) e Brasília (GO); Revista do Instituto } \\
\text { de Medicina Tropical de São Paulo; B1; SciELO. } \\
\text { PegInterferon still has a place in the treatment of } \\
\text { hepatitis C caused by genotype } 3 \text { virus. }\end{array}$ & $\begin{array}{l}\text { Tipo de estudo: transversal, retrospectivo. } \\
\text { Período de análise: jan/2005 a out/2010. } \\
\text { Amostra: } 184 \text { indivíduos infectados com HCV genótipo } 3 \text {, } \\
\text { entre os quais } 114 \text { estavam monoinfectados e } 70 \text { estavam } \\
\text { coinfectados com HIV. } \\
\text { Critérios de inclusão: ter } 18 \text { anos ou mais; ter infecção por } \\
\text { HCV/GEN3 confirmada por meio de um teste de biologia } \\
\text { molecular paraa detecção ou quantificação de RNA viral (RNA } \\
\text { de HCV);ter tomado pelo menos uma dose de Peg-IFN, em } \\
\text { qualquer formadisponível, incluindo Peg-IFN alfa } 2 \text { a (Pesagys, } \\
\text { Roche) ouPeg-IFN alfa } 2 \text { b (Pegintron, MSD), em combinação } \\
\text { comRBV, durante o regime de tratamento de } 24 \text { a } 48 \text { semanas. }\end{array}$ \\
\hline E22 & $\begin{array}{l}\text { Andrade, E. et al.; 2018; Regiões sul, sudeste e } \\
\text { noroeste do Brasil; The Brazilian Journal of } \\
\text { Infectous Diseases; B2; PubMed. } \\
\text { One-step real-time PCR assay for detection and } \\
\text { quantification of RNA HCV to monitor patients } \\
\text { under treatment in Brazil. }\end{array}$ & $\begin{array}{l}\text { Tipo de estudo: ensaio clínico randomizado. } \\
\text { Período de análise: } 2013 \text {. } \\
\text { Amostra: } 611 \text { pacientes pertencentes a hospitais públicos no } \\
\text { sul, sudeste e nordeste do Brasil. } \\
\text { Critérios de inclusão: pacientes com Hepatite C crônica que } \\
\text { iniciaram o tratamento com monoterapia com PEG-IFN. }\end{array}$ \\
\hline E23 & $\begin{array}{l}\text { Ferreira, V. L. et al.; 2018; Curitiba (PR), } \\
\text { Londrina (PR), Cascavel (PR), Ponta Grossa (PR) } \\
\text { e Maringá (PR); The Brazilian Journal of } \\
\text { Infectous Diseases; B2; PubMed. }\end{array}$ & $\begin{array}{l}\text { Tipo de estudo: observacional retrospectivo. } \\
\text { Período de análise: } 2017 \text {. } \\
\text { Amostra: } 176 \text { pacientes que foram tratados em seis centros no } \\
\text { sul do Brasil (Curitiba, Londrina, Cascavel, Ponta Grossa e } \\
\text { Maringá). } \\
\text { Critérios de inclusão: adultos } \geq 18 \text { anos, com diagnóstico e } \\
\text { infecção por HCV que concluíram ou interromperam o } \\
\text { tratamento com DAA de segunda geração antes de abril de } \\
\text { 2017. Foram incluídos independentemente de genótipo, } \\
\text { tratamento anterior ou estágio de fibrose. }\end{array}$ \\
\hline
\end{tabular}




\begin{tabular}{|c|c|c|}
\hline E24 & $\begin{array}{l}\text { Holzmann, I. et al.; 2018; Porto Alegre (RS) } \\
\text { (Hospital SanatórioPartenon); The Brazilian } \\
\text { Journal of Infectous Diseases; B2; SciELO. } \\
\text { Effectiveness of chronic hepatitis C treatment } \\
\text { with direct-acting antivirals in the Public Health } \\
\text { System in Brazil. }\end{array}$ & $\begin{array}{l}\text { Tipo de estudo: transversal, retrospectivo. } \\
\text { Período de análise: dez/2015 a dez/2016. } \\
\text { Amostra: } 1002 \text { pacientes. } \\
\text { Critérios de inclusão: pacientes com CHC submetidos ao } \\
\text { tratamento com DAA. }\end{array}$ \\
\hline E25 & $\begin{array}{l}\text { Pessoa, M. G. et al.; 2018; Brasil (multicêntrico) } \\
-16 \text { centros de referência do Brasil; Annals of } \\
\text { Hepatology; B2; PubMed. } \\
\text { Efficacy and Safety of Ombitasvir/ Paritaprevir/ } \\
\text { Ritonavir and Dasabuvir } \pm \text { Ribavirin for HCV in } \\
\text { Brazilian Adults with advanced Fibrosis. }\end{array}$ & $\begin{array}{l}\text { Tipo de estudo: ensaio clínico randomizado. } \\
\text { Período de análise: não informado. } \\
\text { Amostra: } 222 \text { pacientes. } \\
\text { Critérios de inclusão: adultos a partir de } 18 \text { anos, com } \\
\text { infecção com HCV genótipo } 1 \text {, um RNA de HCV sérico } \\
\text { nível> } 1000 \mathrm{IU} / \mathrm{mL} \text { no momento da triagem e avançado grau de } \\
\text { fibrose hepática, documentada pelos resultados de uma biópsia } \\
\text { hepática } 24 \text { meses antes do recebimento da } 1^{\text {a }} \text { dose do } \\
\text { medicamento do estudo (METAVIR F3, Ishak ou equivalente); } \\
\text { uma biópsia do fígado mostrando cirrose (METAVIR F3/4 ou } \\
\text { F4, Ishak } 5 \text { ou } 6 \text { ou equivalente, em qualquer tempo antes do } \\
\text { recebimento da } 1^{\text {a }} \text { dose do medicamento do estudo; um } \\
\text { resultado de FI de } 9,6 \text { KPa obtido } 6 \text { meses antes da } 1^{\text {a dose do }} \\
\text { tratamento; ou um resultado FibroTest de } 0,59 \text { obtido durante o } \\
\text { período do tratamento. Pacientes com cirrose compensados; } \\
\text { doença hepática (child-Pugh A) sem história anterior de } \\
\text { descompensação; pacientes naive para tratamento e IFN ex- } \\
\text { pacientes eram elegíveis. Pacientes com cirrose deveriam ter } \\
\text { ultrassom, tomografia ou ressonância no período de } 3 \text { meses } \\
\text { antes da triagem, a fim de excluir carcinoma hepatocelular. }\end{array}$ \\
\hline E26 & $\begin{array}{l}\text { Treatment of chronic HCV infection with DAAs } \\
\text { in Rio de Janeiro/Brazil: SVR rates and baseline } \\
\text { resistance analyses in NS5A and NS5B genes. }\end{array}$ & $\begin{array}{l}\text { Tipo de estudo: ensaio clínico randomizado. } \\
\text { Período de análise: } 2015 \text { a } 2017 \text {. } \\
\text { Amostra: } 132 \text { pacientes: } 107 \text { monoinfectados com HCV; } 25 \\
\text { coinfectados HCV/ HIV. } \\
\text { Critérios de inclusão: cumpriram os critérios indicados nas } \\
\text { diretrizes clínicas de } 2015 \text { para o uso de DCV e SOF. Pacientes } \\
\text { que nunca foram tratados com inibidores NS5A e NS5B, } \\
\text { cronicamente infectados com HCV, genótipo } 1 \text { ou 3a com } \\
\text { fibrose avançada (pontuação METAVIR F3) ou cirrose (F4). }\end{array}$ \\
\hline
\end{tabular}

Legenda: CHC - Hepatocarcinoma/Carcinoma Hepatocelular; DAAS - Antivirais de Ação Direta; GTs - Genótipos; HBV - Vírus da Hepatite B; HCV/ VHC - Vírus da Hepatite C; HDV - Vírus da Hepatite D; HIV - Vírus da Imunodeficiência Humana; INF - Interferon; RBV Ribavirina; RNA - Ácido Ribonucleico; RVS - Resposta Virológica Sustentada; ETV - Entecavir; TDF - Tenofovir; BOC - Boceprevir; Peg-IFN (Peguinterferon); ALT - Alanina Aminotransferase; PCR - Reação em cadeira de polimerase; TVR - Telaprevir; MELD - Modelo para doença hepática terminal. Fonte: Autores.

Observou-se na análise do Quadro 1 que a maioria das publicações foram no quadriênio de 2010-2013 (46,1\%), concentradas nas regiões sul e sudeste (49,9\%), em periódicos de hepatologia (23\%), com qualis predominante B1 e B2 $(73,0 \%)$ e em estudos de coorte $(53,8 \%)$.

O Quadro 2 a seguir descreve as principais conclusões de acordo com o tratamento e os respectivos efeitos adversos decorrentes de cada terapêutica escolhida. 
Quadro 2 - Classificação das Hepatites Virais e esquemas terapêuticos com as conclusões e os efeitos adversos, de acordo com os artigos selecionados - Brasil (janeiro de 1998 a dezembro de 2019).

\begin{tabular}{|c|c|c|}
\hline ID & $\begin{array}{c}\text { Classificação da HV } \\
\text { Esquemas terapêuticos }\end{array}$ & Conclusões e efeitos adversos \\
\hline E1 & $\begin{array}{l}\mathrm{HCV} \\
\text { Interferon Alfa e } \\
\text { Ribavirina }\end{array}$ & $\begin{array}{l}\text { Conclusão: considerando-se intenção e conclusão de tratamento, a taxa de resposta viral } \\
\text { sustentada foi de } 32,1 \% \text { ( } 28 \text { de } 87 \text { pacientes) e } 35 \% \text { ( } 28 \text { de } 80 \text { pacientes), } \\
\text { respectivamente. Houve interrupção do tratamento em sete pacientes. A taxa de resposta } \\
\text { sustentada encontrada nesse estudo é compatível à da literatura internacional. Entre os } \\
\text { preditores de eficácia mencionados, apenas a presença dos genótipos } 2 \text { e } 3 \text { mostrou-se } \\
\text { igualmente indicativa de boa resposta na presente série. } \\
\text { Efeitos adversos: alterações hematológicas. }\end{array}$ \\
\hline $\mathbf{E 4}$ & $\begin{array}{l}\mathrm{HCV} \\
\text { INF ALFA } \\
\text { IFN ALFA + RBV, } \\
\text { PEG- IFN + RBV, }\end{array}$ & $\begin{array}{l}\text { Conclusão: entre os pacientes com RVS, não houve recorrência de infecção por HCV ou } \\
\text { evidência de progressão de doença hepática em qualquer paciente acompanhado, por } \\
\text { uma média de } 47 \text { meses após a RVS, exceto para pacientes com doença hepática } \\
\text { avançada antes do tratamento, que podem desenvolver CHC apesar da RVS. Portanto, } \\
\text { pode-se supor que a RVS está associada a um bom prognóstico. } \\
\text { Efeitos adversos: não descrito. }\end{array}$ \\
\hline E5 & $\begin{array}{l}\mathrm{HCV} \\
\mathrm{PEG}-\mathrm{IFN}+\mathrm{RBV}\end{array}$ & $\begin{array}{l}\text { Conclusão: os pacientes desse estudo obtiveram boas taxas de RVS. A análise de } \\
\text { Intenção de Tratar (ITT) mostrou uma RVS de } 22,25 \text { (20/90) nos pacientes infectados } \\
\text { pelo genótipo } 1 \text { e } 40 \%(16 / 40) \text { entre os pacientes infectados pelo genótipo 3. A RVS } \\
\text { também foi menor em pacientes infectados pelo genótipo } 1 \text { (20/79, 25,3\%) em } \\
\text { comparação com } 40 \%(16 / 40) \text { de RVS em pacientes infectados com o genótipo } 3 \text {. } \\
\text { Efeitos adversos: não descrito. }\end{array}$ \\
\hline E6 & $\begin{array}{l}\mathrm{HCV} \\
\mathrm{PEG}-\mathrm{IFN}+\mathrm{RBV}\end{array}$ & $\begin{array}{l}\text { Conclusão:pacientes com cirrose e HCV genótipo 1, idade superior a } 40 \text { anos, carga } \\
\text { viral alta, coinfectados com HIV ou não apresentam baixa RVS se não obtiver PCR } \\
\text { negativo na semana } 12 \text { e devem ser avaliados para interrupção do tratamento. } \\
\text { Efeitos adversos: não descrito. }\end{array}$ \\
\hline E7 & $\begin{array}{l}\mathrm{HCV} \\
\text { PEG - IFN + RBV }\end{array}$ & $\begin{array}{l}\text { Conclusão: mulheres e homens exibem semelhantes características clínicas, } \\
\text { histológicas e virológicas da doença antes do início do tratamento, mas eles reagem de } \\
\text { forma diferente à terapia combinada, especialmente no que diz respeito à incidência de } \\
\text { eventos adversos, que são mais frequentes entre as mulheres. } \\
\text { Efeitos adversos: anemia, neutropenia, sintomas psiquiátricos (tontura, depressão, } \\
\text { irritabilidade), perda de peso, anorexia, insônia, alopecia. }\end{array}$ \\
\hline E10 & $\begin{array}{l}\mathrm{HCV} \\
\text { Alfainterferona e } \\
\text { Ribavirina }\end{array}$ & $\begin{array}{l}\text { Conclusão: a combinação de IFN e Ribavirina na amostra do estudo mostrou um perfil } \\
\text { de eventos adversos como esperado e RVS semelhante a estudos locais de eficácia para } \\
\text { esse tratamento, garantindo segurança e eficácia do medicamento produzido por Bio- } \\
\text { Manguinhos. } \\
\text { Efeitos adversos: fadiga, cefaleia, mialgia, irritabilidade e pele seca. Efeitos adversos } \\
\text { graves: hiponatremia, ruptura de varizes esofágicas, exacerbação da enxaqueca; } \\
\text { resultaram em interrupção do tratamento. }\end{array}$ \\
\hline E11 & $\begin{array}{l}\text { HCV } \\
\text { Peg Interferon }+ \\
\text { Ribavirina }+ \\
\text { Boceprevir ou } \\
\text { Telaprevir }\end{array}$ & $\begin{array}{l}\text { Conclusão: os pacientes que completaram o tratamento tiveram maior chance de atingir } \\
\text { a RVS. No entanto, as taxas de RVS alcançadas por diferentes centros em todo o Brasil } \\
\text { foram muito mais baixas que as taxas nos estudos de aprovação. Em 2015, o MS } \\
\text { interrompeu o uso do Boceprevir e Telaprevir. As novas drogas incorporadas } \\
\text { (Daclatasvir, Simeprevir e Sofosbuvir) oferecem maior eficácia e segurança. O uso do } \\
\text { Peg-Interferon é limitado por seus efeitos colaterais e a indicação da Ribavirina } \\
\text { permanece muito específica. } \\
\text { Efeitos adversos: anemia, leucopenia, trombocitopenia, erupções cutâneas e infecção } \\
\text { severa. }\end{array}$ \\
\hline E12 & $\begin{array}{l}\text { HBV } \\
\text { IFN, LAM + TDF, } \\
\text { LAM + ADV, LAM + } \\
\text { ETV; } \\
\text { ADV, TDF ou ETV }\end{array}$ & $\begin{array}{l}\text { Conclusão: relata-se uma visão geral do estado atual da terapia antiviral contra doenças } \\
\text { crônicas por Hepatite B no Brasil. Além disso, avaliou a frequência de positividade de } \\
\text { HBV DNA e resistência a LAM em mutações importantes em diferentes terapias. Trata- } \\
\text { se de uma diferença no padrão de variantes YMDD entre os principais genótipos que } \\
\text { circulam no Brasil. Variantes YVDD foram encontradas em } 12 / 13(92 \%) \text { do genótipo A, } \\
\text { enquanto a variação YIDD foi encontrada com mais frequência nos genótipos D }(6 / 11 \text {; } \\
54 \%) \text { e F, }(2 / 3 ; 67 \%) \text {. O número de mutações também foi associado ao genótipo, como o }\end{array}$ \\
\hline
\end{tabular}




\begin{tabular}{|c|c|c|}
\hline & & $\begin{array}{l}\text { YMDD, em que a trimutação era mais comum no genótipo D, enquanto a maioria dos } \\
\text { isolados do genótipo A tinha um YMDD duplo mutação. } \\
\text { Efeitos adversos: não descrito. }\end{array}$ \\
\hline E13 & $\begin{array}{l}\mathrm{HCV} \\
\mathrm{PEG}-\mathrm{IFN}+\mathrm{RBV} \\
\text { Amantadina }\end{array}$ & $\begin{array}{l}\text { Conclusão: uma proporção substancial de pacientes que não responderam ou tiveram } \\
\text { recaída após o tratamento com Interferon convencional mais Ribavirina atingiram a } \\
\text { RVS quando retratados Peguinterferon alfa- } 2 \text { a }(40 \mathrm{KD}) \text { mais Ribavirina. A Amantadina } \\
\text { não melhora a RVS e não pode ser indicada nesse cenário. } \\
\text { Efeitos adversos: leucopenia, neutropenia, trombocitopenia, fadiga e anemia. }\end{array}$ \\
\hline E14 & $\begin{array}{l}\mathrm{HCV} \\
\text { Interferon peguilado e } \\
\text { Ribavirina }\end{array}$ & $\begin{array}{l}\text { Conclusão: níveis de HCR-RNA são mais frequentemente detectados de forma mais } \\
\text { elevada no soro que nas plaquetas.Novos estudos com um aumento no tamanho das } \\
\text { amostras nessa população são necessários para avaliar melhor se os pacientes que } \\
\text { apresentaram HCV-RNA em níveis baixos nas plaquetas, após terem perdido HCV-RNA } \\
\text { detectável no soro durante a terapia antiviral, apresentam um risco aumentado de } \\
\text { recidiva da infecção por HCV durante a avaliação de acompanhamento. } \\
\text { Efeitos adversos: trombocitopenia. }\end{array}$ \\
\hline E15 & $\begin{array}{l}\mathrm{HCV} \\
\text { Peg Interferon e } \\
\text { Ribavirina }\end{array}$ & $\begin{array}{l}\text { Conclusão: a taxa de RVS foi baixa em pacientes idosos. Essa resposta não foi devido à } \\
\text { baixa tolerância, mas principalmente às condições de pré-tratamento. Entre os pacientes } \\
\text { idosos, os melhores candidatos ao tratamento da Hepatite C são aqueles com níveis } \\
\text { elevados de hemoglobina pré-tratamento e controle glicêmico adequado. } \\
\text { Efeitos adversos: fadiga, anemia, descompensação hepática, alergia e vasculite. }\end{array}$ \\
\hline E16 & $\begin{array}{l}\mathrm{HCV} \\
\text { Interferon preguilado e } \\
\text { Ribavirina }\end{array}$ & $\begin{array}{l}\text { Conclusão: a RVS foi satisfatória para pacientes transplantados e diminuiu com o } \\
\text { aumento da idade. A não exposição prévia ao transplante de drogas antivirais teve } \\
\text { impacto positivo na chance de RVS. A sobrevida global foi similar em respondedores e } \\
\text { não respondedores. } \\
\text { Efeitos adversos: descompensação clínica, astenia grave, rejeição. }\end{array}$ \\
\hline E17 & $\begin{array}{l}\text { HDV } \\
\text { Peg- IFN + ETV }\end{array}$ & $\begin{array}{l}\text { Conclusão: monitoramento da CV; todos os pacientes que apresentavam HDV } \\
\text { indetectável na semana } 24 \text { continuaram a apresentar até o término do tratamento e } \\
\text { também durante o acompanhamento. Fortalecer a ideia de que a terapia combinada é } \\
\text { eficaz no tratamento de HDV-3 em pacientes de etnia não europeia. É o primeiro estudo } \\
\text { a demonstrar um protocolo terapêutico eficaz que pode ser seguido em pacientes com } \\
\text { genótipo } 3 \text {. } \\
\text { Efeitos adversos foram relacionados à administração de PEG-IFN: artralgia, mialgia, } \\
\text { astenia, perda de peso, cefaleia, epigastralgia, febre, diarreia, tontura. }\end{array}$ \\
\hline E18 & $\begin{array}{l}\text { HBV } \\
\text { TDF ou ETV }\end{array}$ & $\begin{array}{l}\text { Conclusão: foi mostrado que ambos os medicamentos (ETV e TDF) têm uma alta taxa } \\
\text { de Negativação HBV VL e excelente perfil de segurança. } \\
\text { Efeitos adversos: não houve registro de ocorrência de efeitos adversos, como perda da } \\
\text { função renal. }\end{array}$ \\
\hline E19 & $\begin{array}{l}\text { HCV } \\
\text { Interferon e Ribavirina } \\
\text { ou Interferon peguilado } \\
\text { e Ribavirina }\end{array}$ & $\begin{array}{l}\text { Conclusão: menor taxa de RVS; maior percentual de RVS com o uso do Interferon } \\
\text { convencional, provavelmente se deve ao baixo número de pacientes tratados com } \\
\text { genótipo 1(tem menor resposta à terapia); maiores taxas de RVS entre os pacientes que } \\
\text { apresentaram, à análise genética, expressão CC do polimorfismo do IL28B; ratificaram } \\
\text { a baixa eficácia da terapia dupla com Interferon e Ribavirina em um estudo de vida real. } \\
\text { Efeitos adversos: não descrito }\end{array}$ \\
\hline E20 & $\begin{array}{l}\text { HCV } \\
\text { Peg-Interferon, } \\
\text { Ribavirina e } \\
\text { Boceprevir ou } \\
\text { Telaprevir }\end{array}$ & $\begin{array}{l}\text { Conclusão: embora a maioria tenha alcançado RVS após o tratamento, a taxa de SAEs } \\
\text { foi muito alta nessa população. Os pacientes com cirrose tiveram um risco menor de } \\
\text { atingir RVS e um risco aumentado de desenvolver SAEs. Portanto, o risco de } \\
\text { desenvolvimento de EAGs, incluindo complicações clínicas graves e morte, } \\
\text { principalmente naqueles com doença hepática avançada, deve ser considerado. } \\
\text { Confirmam a necessidade de reformulação das diretrizes para o tratamento da Hepatite C } \\
\text { crônica no Brasil. } \\
\text { Efeitos adversos:anemia, erupção cutânea, neutropenia e trombocitopenia. }\end{array}$ \\
\hline E21 & $\begin{array}{l}\text { HCV } \\
\text { Peg-Interferon e } \\
\text { Ribavirina }\end{array}$ & $\begin{array}{l}\text { Conclusão: ter a coinfecção com HIV não alterou as chances de RVS ou a frequência } \\
\text { de SAEs; taxa de sucesso terapêutico satisfatória para os infectados pelo GEN3. } \\
\text { Efeitos adversos: anemia, trombocitopenia, intolerância ao tratamento, complicações } \\
\text { infecciosas ou qualquer outro evento adverso grave. }\end{array}$ \\
\hline
\end{tabular}




\begin{tabular}{|c|c|c|}
\hline E22 & $\begin{array}{l}\mathrm{HCV} \\
\text { Interferon Alfa } \\
\text { Peguilado }\end{array}$ & $\begin{array}{l}\text { Conclusão: o ensaio RT-PCR em tempo real de uma etapa demonstrou bom } \\
\text { desempenho na mediação da CV e no monitoramento do tratamento. Em suma, o teste } \\
\text { BioM HCV VL provou ser adequado para monitorar pacientes com infecção VHC } \\
\text { crônica em tratamento com antiviral. } \\
\text { Efeitos adversos:não descrito. }\end{array}$ \\
\hline E23 & $\begin{array}{l}\mathrm{HCV} \\
\text { SOF/DCV ou } \\
\text { SOF/SIM }\end{array}$ & $\begin{array}{l}\text { Conclusão: confirmam que a segunda geração DAAs é eficaz para o tratamento da } \\
\text { Hepatite C crônica, em especial para genótipo } 1 \text {. O genótipo } 3 \text { parece ser o mais difícil } \\
\text { de tratar, mesmo assim as taxas atuais de SVR com DAAs de segunda geração } \\
\text { forammaiores que com as terapias anteriores. } \\
\text { Efeitos adversos: epigastralgia (IFN, SOF e RBV), hemorragia digestiva (SOF/DCV) e } \\
\text { um não descrito (SOF/DVC). }\end{array}$ \\
\hline E24 & $\begin{array}{l}\mathrm{HCV} \\
\text { SOF/SIM ou } \\
\text { SOF/DCV }\end{array}$ & $\begin{array}{l}\text { Conclusão: tratar do CHC com os regimes terapêuticos nacionais alcançou altas taxas } \\
\text { de RVS, incluindo pacientes com cirrose. Sexo e duração do tratamento em pacientes } \\
\text { infectados com o genótipo 1, que receberam SOF e DAC com ou sem RIB, } \\
\text { influenciaram significativamente a RVS. } \\
\text { Efeitos adversos: não descrito. }\end{array}$ \\
\hline E25 & $\begin{array}{l}\text { HCV } \\
\text { Ombitasvir, } \\
\text { Paritaprevir, Ritonavir } \\
\text { e Dasabuvir +/- } \\
\text { Ribavirina }\end{array}$ & $\begin{array}{l}\text { Conclusão: o tratamento com o regime 3-DAA com RBV, ou sem RBV, é seguro e pode } \\
\text { ser uma opção eficaz para tratar a infeç̧ão crônica pelo HCV GT, com fibrose ou cirrose } \\
\text { (METAVIR F3/4). O 3-DAA com-sem RBV é adequado para pacientes infectados com } \\
\text { GT1b sem cirrose, enquanto o regime de 3-DAA com RBV maximiza a eficácia em } \\
\text { pacientes GT1b com cirrose e em todos os pacientes GT1a. } \\
\text { Efeitos adversos:dor de cabeça, fadiga, náuseas e prurido. }\end{array}$ \\
\hline E26 & $\begin{array}{l}\mathrm{HCV} \\
\text { SOF/ DCV com ou sem } \\
\text { Ribavirina }\end{array}$ & $\begin{array}{l}\text { Conclusão: a taxa de RVS em pacientes cronicamente infectados com HCV e tratados } \\
\text { com regime DAA DDV/SOF }(95,4 \%) \text { foi semelhante aos resultados dos ensaios clínicos } \\
\text { randomizados. Substituições de aminoácidos não tiveram impactos negativos no } \\
\text { resultado do tratamento, especialmente para o genótipo } 1 \text { b, uma vez que os pacientes } \\
\text { alcançaram a RVS. Isso demonstra a importância de uma terapia combinada dirigida e } \\
\text { diferentes proteínas virais. Sugere-se a combinação de DAAs, como } \\
\text { OBV/DSV/PRV/SOF/LED e EBV/GZV, em protocolos futuros para os portadores } \\
\text { crônicos de HCV. } \\
\text { Efeitos adversos: cefaleia, anemia, náuseas e fadiga. }\end{array}$ \\
\hline
\end{tabular}

Legenda: ADV - Adefovir, CHC - Hepatocarcinoma/Carcinoma Hepatocelular, DAAS/AADS - Antivirais de Ação Direta, ETV - Entecavir, EVR - Resposta Virológica Precoce, GTs - Genótipos, HBV - Vírus da Hepatite B, HCV - Vírus da Hepatite C, HDV - Vírus da Hepatite D, HIV - Vírus da Imunodeficiência Humana, IFN - Interferon, LAM - Lamivudina, PCR - Proteína C Reativa, PEG-IFN ou INF - PegInterferon ou Interferon peguilado, RBV - Ribavirina, RNA - Ácido Ribonucleico, RVR - Resposta Virológica Rápida, RVS - Resposta Virológica Sustentada, SOF/DCV - Sofosbuvir/Daclatasvir, SOF/SIM - Sofosbuvir/Simeprevir, TDF - Tenofovir, TH - Transplante Hepático, TV - Transmissão Vertical, MS - Ministério da Saúde, DAC - Daclatasvir, SAES - Evento Adverso Significativo, EAG - Evento Adverso Grave. Fonte: Autores.

Conforme apresentado no Quadro 2 a temática "tratamento" foi relatada em 84,6\% (n=22). Os estudos evidenciaram o tratamento da Hepatite C em 86,3\% (n=19), da Hepatite B em 9,0\% (n=2) e da Hepatite D em 4,5\% (n=1). Destacam-se as publicações referentes ao tratamento da Hepatite C, com uso da terapêutico Interferon com ou sem Ribavirina (76,3\%) e os principais efeitos adversos cefaleia, anemia e fadiga.

Para a Hepatite C, os autores descreveram o uso do Interferon e seus derivados em 63,1\% ( $\mathrm{n}=12)$, de Interferon mais associações (Boceprevir, Telaprevir e Amantadina) em 10,5\% (n=2) e o uso dos antivirais de ação direta (DAAS) em 26,3\% $(n=5)$.

O Quadro 3 descreve as conclusões das estratégias desenvolvidas em cada local de estudo e suas respectivas recomendações em prol da prevenção e do controle das HV em seres humanos, representando 15,3\% (4) dos artigos selecionados. 
Quadro 3 - Fatores associados à classificação das Hepatites Virais e as estratégias de prevenção e controle com as conclusões e as principais recomendações, de acordo com os artigos pesquisados (Brasil).

\begin{tabular}{|c|c|c|c|}
\hline ID & HV & $\begin{array}{l}\text { Estratégias de } \\
\text { prevenção/ } \\
\text { controle }\end{array}$ & Conclusões e recomendações \\
\hline E2 & $\mathrm{HBV}$ & $\begin{array}{l}\text { Prevenção: } \\
\text { Vacina }\end{array}$ & $\begin{array}{l}\text { Conclusão: o aumento dos marcadores de Hepatite B ao longo da adolescência } \\
\text { reforça os benefícios da vacinação antes do envolvimento em atividades que } \\
\text { colocam o indivíduo em risco de infecção pelo HBV. } \\
\text { Recomendações: } \\
\text { Aumentar a cobertura da vacina contra Hepatite b em adolescentes; imunização na } \\
\text { escola pode ser uma estratégia. }\end{array}$ \\
\hline $\mathbf{E 3}$ & $\mathrm{HBV}$ & $\begin{array}{l}\text { Prevenção: } \\
\text { Vacina }\end{array}$ & $\begin{array}{l}\text { Conclusão: os resultados enfatizam dimensionar a necessidade urgente de } \\
\text { educação em saúde adicional aos programas de vacinação e vacina alternativa } \\
\text { contra Hepatite B, horários alternativos para melhorar a cobertura vacinal em } \\
\text { comunidades remanescentes de quilombos, um reservatório de HBV no Brasil } \\
\text { Central, uma área considerada de baixa endemicidade da Hepatite B. Embora a } \\
\text { maioria tenha cumprido a primeira dose da vacina, apenas metade fez a segunda } \\
\text { dose, e um terço completou a terceira dose. } \\
\text { Recomendações: } \\
\text { Promover educação em saúde além dos programas de vacinação já existentes; } \\
\text { ampliar esquemas de vacinação; otimizar cobertura vacinal. }\end{array}$ \\
\hline E8 & $\mathrm{HCV}$ & $\begin{array}{l}\text { Controle: } \\
\text { Monitoramento } \\
\text { de gestantes }\end{array}$ & $\begin{array}{l}\text { Conclusão: a elevada viremia materna e uso de drogas pela mãe estão associados à } \\
\text { transmissão vertical do HCV. } \\
\text { Recomendações: } \\
\text { Organizar os serviços especializados no atendimento de gestantes (concentrar as } \\
\text { informações referentes aos atendimentos em um único lugar). }\end{array}$ \\
\hline E9 & $\mathrm{HBV}$ & $\begin{array}{l}\text { Controle: } \\
\text { Resposta à } \\
\text { vacinação em } \\
\text { estudantes de } \\
\text { graduação e } \\
\text { profissionais de } \\
\text { Saúde }\end{array}$ & $\begin{array}{l}\text { Conclusão: mostra a importância de melhorar conhecimento e consciência da } \\
\text { Hepatite B entre os profissionais de Saúde prestadores de cuidados, especialmente } \\
\text { em países em desenvolvimento, como o Brasil. } \\
\text { Recomendações: } \\
\text { Sugere-se aos profissionais de Saúde considerarem o cartão de vacinação como um } \\
\text { importante documento para registrar suas histórias clínica e ocupacional. } \\
\text { Melhorar o conhecimento e a conscientização sobre a Hepatite B entre os } \\
\text { profissionais de Saúde e estudantes de ensino superior; considerar a carteira de } \\
\text { vacinação na história clínica e ocupacional. }\end{array}$ \\
\hline
\end{tabular}

Legenda: HBV - Vírus da Hepatite B, HCV ou VHC - Vírus da Hepatite C. Fonte: Autores.

Evidenciou-se na análise do Quadro 3 que a vacinação foi a principal estratégia retratada para a prevenção da transmissão da Hepatite B e que recomenda-se fortemente o aumento da cobertura vacinal.

\section{Discussão}

Propôs-se, com esta revisão, investigar a produção científica nacional sobre as estratégias de prevenção, controle e tratamento acerca das HV, publicada no período de 1998 a 2019. Mediante a relevância dessa problemática, buscou-se elucidar de que maneira essas iniciativas têm sido abordadas e retratadas na literatura.

Houve a necessidade de compreensão das estratégias para o enfrentamento das HV propostas pelo MS a partir de 1998, consideradas nesta revisão, haja vista que a quantidade de estudos produzidos sobre o assunto foi maior de 2010 a 2013 e de 2014 a 2018. 
Destaca-se que, nesse período, houve a introdução dos antivirais de ação direta, os quais proporcionaram grandes ganhos em qualidade de vida e eficácia do tratamento, devido à diminuição significativa de eventos adversos e à melhora na resposta virológica sustentada (RVS), o que pode justificar uma maior produção científica.

Denota-se uma fragilidade de pesquisas voltadas para as Práticas Baseadas em Evidências (PBE) nesse cenário. O conceito de PBE busca agregar melhor conhecimento científico, aliado à experiência clínica e à escolha do paciente. Trata-se de uma prática fundamental na área da Saúde. Cabe destacar que, na enfermagem, essa iniciativa otimiza a sistematização da assistência, possibilitando a promoção de um cuidado fundamentado, seguro e livre de danos (Schineider, Pereira, \& Ferraz, 2018).

Visando fortalecer as PBE, o Brasil aderiu à campanha de amplitude internacional intitulada "Nursing Now", uma iniciativa da OMS e do Conselho Internacional de enfermeiros, em parceria com o Conselho Federal de Enfermagem (COFEN), que intenta fortalecer e valorizar os profissionais de enfermagem no enfretamento dos desafios de Saúde do século XXI.

A seguir, serão apresentadas e discutidas as duas categorias analíticas expressas nos resultados dos artigos selecionados: tratamento e estratégias de prevenção e controle.

\subsection{Categoria 1: tratamento}

A terapia com Interferons teve seu início no Brasil na década de 90, e os estudos descrevem baixas e regulares taxas de RVS, associadas a muitos efeitos adversos que culminavam em abandono e sucessivas interrupções do tratamento (Souza et al., 2004; Mourão et al., 2008). A partir de 2001, associou-se o Interferon à Ribavirina, aumentando a RVS, no entanto, mantendo a quantidade de efeitos adversos (Ferreira \& Pontarolo, 2017).

Nesse aspecto, em 2015, a implantação dos antivirais de ação direta revolucionou o tratamento da Hepatite C, até então árduo e de difícil manejo. Estes fármacos agem inibindo a replicação viral e atuam em diferentes estágios do processo de replicação (Medeiros, Farias, Farias \& Macedo, 2020). Segundo Brasil (2018a), essa classe de medicamentos ocasiona um menor número de efeitos adversos, com consequente diminuição das taxas de interrupção e abandono. Além disso, resulta em alta efetividade terapêutica, ou seja, RVS.

Por fim, ressalta-se que os achados desta revisão referentes ao tratamento da Hepatite C vão ao encontro da iniciativa do MS de erradicar o HCV no Brasil até 2030 (Brasil, 2018b).

O tratamento da Hepatite B foi abordado em 9,0\% dos trabalhos, porém não deve ser considerado menos importante. O primeiro protocolo clínico comas diretrizes terapêuticas data de 2002 e introduzo uso do Interferon-alfa e da Lamivudina (Brasil, 2002a).

A Lamivudina foi o primeiro análogo nucleosídeo aprovado para o tratamento da Hepatite B, com a vantagem de ser administrada por via oral e resultar em poucos eventos adversos. Contudo, destaca-se a desvantagem de selecionar cepas mutantes, resultando em resistência, proporcional ao tempo de uso da droga (Brasil, 2002a; Ferreira, 2000; Moreira\& Areias, 2008).

Em 2009, foram incorporados simultaneamente o Adeforvir, o Entecavir e o Tenofovir, resultando em melhor custoefetividade no uso da terapêutica. Ademais, recomendou-se o uso de associações medicamentosas em casos de resistência viral (Brasil, 2009).

Buscando simplificar o arsenal para o tratamento da Hepatite B, o PCDT de 2017 amplia a indicação de uso do Tenofovir e do Entecavir por apresentarem maior eficácia e barreira genética e introduziu o uso da Alfapeguinterferona, uma citocina com ação antiviral e imunomoduladora, conferindo maior facilidade posológica e menos efeitos adversos (Brasil, 2017). 
Por fim, está em estudo uma vacina terapêutica para a Hepatite B (NASVAC), a qual proporciona esperança aos acometidos cronicamente pelo agravo, prometendo a sua cura funcional. A saber, um estudo acompanhou 71 indivíduos durante 18 meses e os pesquisadores concluíram que a vacina é segura e eficaz para alcançar a cura funcional em pacientes com Hepatite B crônica (Yoshida et al., 2020).

Esta revisão inclui dois estudos sobre o tratamento de pacientes com hepatite B, sendo que, em um, o autor avaliou a positividade do DNA HBV e a resistência aos medicamentos associados aos genótipos e evidenciou que, apenas na associação LAM + ETV, não houve positividade do DNA HBV. Já no segundo estudo, o autor avaliou a eficácia dos nucleotídeos (TDV) e nucleosídeos (ETV) e demonstrou altas taxas de negativação do DNA HBV e excelente perfil de segurança, o que vai ao encontro das diretrizes propostas.

A Hepatite D foi retratada em 4,5\% dos estudos e, assim como a Hepatite B, esse agravo também não tem cura. O estudo encontrado nesta revisão avaliou a resposta ao tratamento do HDV, genótipo 3 com Peg-Interferon e Entecavir, com $86,4 \%$ de sucesso. Evidenciam-se os eventos adversos mialgia e astenia referentes ao uso do Interferon, relatados por todos os pacientes.

Todos os pacientes portadores da Hepatite Delta são candidatos à terapia com Alfapeguinterferona (Brasil, 2020c). Em 2020, a Sociedade Brasileira de Hepatologia recomendou que qualquer genótipo do HDV seja tratado com Interferon peguilhado alfa 2a (Paraná et al., 2015).

Diante da importância dessa temática, o MS lançou, em 2020, um painel informativo sobre o tratamento das hepatites. Em 2019, 37 mil pessoas estavam em tratamento para a Hepatite B e 36 mil pessoas trataram a Hepatite C (Brasil, 2020d).

Desse modo, esforços são somados e o combate às HV constitui prioridade pactuada entre as entidades representantes do MS, vislumbrando constante revisão das estratégias empregadas nas políticas de Saúde (Brasil, 2020a).

\subsection{Categoria 2: estratégias de prevenção e controle}

As estratégias de prevenção e controle foram apresentadas em 15,3\% $(n=4)$ dos artigos encontrados. Os estudos abordaram temas como a prevalência de infecção por Hepatite $\mathrm{C}$ em gestantes e a taxa de transmissão vertical, assim como a epidemiologia da Hepatite B em determinados grupos, a adesão ao esquema vacinal e a resposta imunológica à vacina.

Em relação às gestantes com sorologia positiva para Hepatite $C$, os autores identificaram uma prevalência de $0,2 \%$ gestantes portadoras do vírus. Além disso, houve uma associação significativa entre transmissão materno-fetal e alta viremia sérica materna e uso de drogas ilícitas pela mãe (Gardenal et al., 2011).

Esses resultados corroboram os dados apresentados no relatório sobre testagem universal para Hepatite Viral C em gestantes, no pré-natal, do MS. Além das chances de complicação da evolução da doença, como cronicidade, cirrose hepática e câncer hepático, essas gestantes podem apresentar maior risco para desenvolvimento de diabetes gestacional, pré-eclâmpsia, hemorragia e parto prematuro (Brasil, 2020d).

Dessa forma, a possibilidade de ampliação da testagem para o vírus da Hepatite $\mathrm{C}$ em gestantes no pré-natal, tornando-a universal no SUS, vem sendo avaliada, com o intuito de melhorar a oferta de tratamento e prevenção da transmissão vertical de Hepatite C (Brasil, 2020d).

Os dados apresentados em dois estudos incluídos na revisão (Oliveira et al, 2006; Motta-Castro et al, 2009) indicam que, apesar da importância da prevenção da Hepatite B por meio da vacinação e da disponibilização dos imunizantes pelo Sistema Único de Saúde nos calendários vacinais, para todas as faixas etárias, ainda é possível identificar uma cobertura vacinal aquém do esperado, especialmente para populações mais vulneráveis.

Essas informações condizem com os dados do MS, os quais revelam que há maior risco de exposição à doença em áreas com maior dificuldade de acesso aos serviços de Saúde. Além dessa população, podemos destacar os profissionais da 
área da Saúde como outro grupo bastante vulnerável às HV, devido ao risco ocupacional pela exposição a materiais biológicos potencialmente contaminados (Brasil, 2017).

A Hepatite B apresenta um importante impacto na saúde pública, uma vez que constitui a segunda maior causa de óbitos entre as HV, além de estar relacionada à morbidade e à diminuição da qualidade de vida dos indivíduos. Essas informações reforçam a necessidade de melhorar e fortalecer as estratégias de prevenção da doença, especialmente por meio da vacinação, que é considerada pelo MS uma prioridade para prevenir a transmissão (Brasil, 2019).

A saber, a vacina contra a Hepatite B foi implantada no Brasil a partir de 1997 e, até então, era destinada a profissionais da área da Saúde e a pessoas menores de 20 anos de idade. A partir do ano 2000, passou a compor o calendário básico de vacinação (Brasil, 2017). Ressalta-se que tomar a vacina não necessariamente garante a imunização, visto que até $10 \%$ da população não irá produzir anticorpos contra o $\mathrm{HBV}$, sendo pois, necessária a realização de exames após a vacinação (Rodrigues Neto, et al. 2020).

Por fim, os estudos levantados nesse contexto (Oliveira et al, 2006; Motta-Castro et al, 2009; Carvalho et al, 2012) demonstraram que a resposta à vacina contra Hepatite B não foi desenvolvida em todos os indivíduos. Os autores descreveram que a soroconversão se relaciona à idade dos participantes da pesquisa, explicando o motivo de os estudantes da área da Saúde e os adolescentes apresentarem melhores respostas imunológicas após a vacinação.

\section{Considerações Finais}

Esta revisão evidenciou um número expressivo de publicações sobre a segurança e a efetividade dos fármacos utilizados para o tratamento da Hepatite C. Foram detectadas, entre outros fatores, a eficácia e a durabilidade da RVS, o que vai ao encontro das diretrizes do Departamento de Doenças de Condições Crônicas e Infecções Sexualmente Transmissíveis (DCCC/IST) para o biênio 2019-2020.

Evidenciou-se, também, uma carência em publicações sobre estratégias de prevenção e controle, ficando estas, em sua maioria, a cargo do MS, contempladas em seus protocolos clínicos e em suas diretrizes terapêuticas. Neste sentido, o implemento de estratégias adequadas ao controle e prevenção poderão resultar em menor dispêndio de energia com o tratamento, uma vez que o foco estará direcionado para ações de precaução da ocorrência da moléstia.

Enfim, ressaltam-se a importância de se manterem os esforços para o controle e o tratamento desse agravo tão prevalente e devastador em nosso país e a necessidade de intensificar estudos sobre prevenção e controle das HV em todo o território nacional. Sugere-se a realização de estudos adicionais a fim de elucidar o conhecimento e conter o avanço do agravo.

\section{Referências}

Almeida, E. C. et al. (2019). Access to viral hepatitis care: distribution of health services in the Northern region of Brazil. Revista Brasileira de Epidemiologia, 22(1), e190008. https://dx.doi.org/10.1590/1980-549720190008.supl.1

Botelho, L. L. R, Cunha, C. C. de A., \& Macedo, M. (maio/ago 2011). O método da revisão integrativa nos estudos organizacionais. Gestão e Sociedade, 5(11), 121-136. https://www.gestaoesociedade.org/gestãoesociedade/article/view/1220

Câmara dos Deputados. Centro de Documentação e Informação. (2016). Decreto $n^{o} 8.901$, de 10 de novembro de 2016. Brasília. https://www2.camara.leg.br/legin/fed/decret/2016/decreto-8901-10-novembro-2016-783905-normaatualizada-pe.html

Carvalho P. et al. (maio/jun. 2012). Prevalência do vírus da hepatite B e resposta à vacinação em profissionais de Saúde e estudantes da Universidade Federal da Bahia, Brasil. Hepatol, Hn 11(3), 330-7. BR\&sl=en\&u=https://pubmed.ncbi.nlm.nih.gov/22481451/\&prev=search\&pto=aue

Fabbri, S., Silva, C., Hernandes, E. M., Octaviano, F. R., Di Thommazo, A., \& Belgamo, A. (2016). Improvements in the Start tool to better support the systematic review process. In: EASE '16: Proceedings of the 20th International Conference on Evaluation and Assessment in Software Engineering, (21): 1-5. Limerick, Ireland. https://doi.org/10.1145/2915970.2916013

Ferreira, M. S. Diagnóstico e tratamento da hepatite B. (2000) Revista da Sociedade Brasileira de Medicina Tropical,33(4): 389-400. https://www.scielo.br/pdf/rsbmt/v33n4/2493.pdf 
Ferreira, V. L., \& Pontarolo, R. (2017). Contextualização e avanços no tratamento da Hepatite C: uma revisão da literatura. Visão Acadêmica (Curitiba), 18(1). https://revistas.ufpr.br/academica/article/view/51007

Galvão, C. M. (2006). Níveis de evidência [editorial]. Acta Paul Enferm, 19(2): V.

Gardenal, R. V. C. et al. (2011).Hepatite C e gravidez: uma análise dos fatores associados a transmissão vertical. Revista da Sociedade Brasileira de Medicina Tropical, 44(1): 43-47. https://doi.org/10.1590/S0037-86822011000100011

Liberati, A. et al. (2009). The PRISMA Statement for Reporting Systematic Reviews and Meta-Analyses of Studies That Evaluate Health Care Interventions: Explanation and Elaboration. Plos Medicine.https://doi.org/10.1371/journal.pmed.1000100

Medeiros, G. R. de, Farias, I. C. C., Farias, J. V. C., Macedo, P. R. de. (2020). Terapias antivirais anti-HCV como alternativa para o tratamento de Covid 19. Research, Society and Development, 9(10), e9489109406, 2020. 10.33448/rsd-v9i10.9406. https://rsdjournal.org/index.php/rsd/article/view/9406

Mendes, K. D. S., Silveira, R. C. C. P., \& Galvão, C. M. (2008). Revisão integrativa: método de pesquisa para a incorporação de evidências na saúde e na enfermagem. Texto \& Contexto - Enfermagem, 17(4), 758-764. https://dx.doi.org/10.1590/S0104-07072008000400018

Ministério da Saúde. (2002). Portaria $n^{o} 263$, de 5 de fevereiro de $2002 . \quad$ Brasília. http://bvsms.saude.gov.br/bvs/saudelegis/gm/2002/prt0263_05_02_2002.html

Ministério da Saúde. (2002). Portaria $n^{o}$ 860, de 12 de novembro de 2002. Protocolo Clínico e Diretrizes Terapêuticas. Hepatite Viral Crônica B. Medicamentos: Lamivudina, Interferon-alfa Brasília. http://aigabrasil.org/leis/port_860.html

Ministério da Saúde. (2009). Portaria $n^{\circ}$ 2561, de 28 de outubro de 2009. Aprova o Protocolo Clínico e Diretrizes Terapêuticas - Hepatite Viral Crônica B e Coinfecções. Brasília. http://bvsms.saude.gov.br/bvs/saudelegis/gm/2009/prt2561_28_10_2009.html

Ministério da Saúde. (2013). Décadas de 1990 e 2000 reforçam sucesso do programa nacional de imunizações. Blog da Saúde (Brasília). http://www.blog.saude.gov.br/index.php/servicos/32998-decadas-de-1990-e-2000-reforcam-sucesso-do-programa-nacional-de-imunizacoes

Ministério da Saúde. Secretaria de Vigilância em Saúde. (2019). Boletim Epidemiológico de Hepatites Virais - 2019. Brasília. http://www.aids.gov.br/ptbr/pub/2019/boletim-epidemiologico-de-hepatites-virais-2019

Ministério da Saúde. Secretaria de Vigilância em Saúde. Departamento de condições crônicas e infecções sexualmente transmissíveis. (jul. 2020b). Dia Mundial de Luta contra as hepatites virais. Brasil zera fila de tratamento de hepatites virais e garante estoque até 2021. http://www.aids.gov.br/ptbr/noticias/brasil-zera-fila-de-tratamento-de-hepatites-virais-e-garante-estoque-ate-2021

Ministério da Saúde. Secretaria de Vigilância em Saúde. Departamento de DST, Aids e Hepatites Virais. (2017). Protocolo Clínico e Diretrizes Terapêuticas para Hepatite B e Coinfecções. Brasília: Ministério da Saúde. 120 p.

Ministério da Saúde. Secretaria de Vigilância em Saúde. Departamento de condições crônicas e infecções sexualmente transmissíveis. (2018a). Saúde lança plano para acabar com a hepatite $C$ até 2030 . http://www.aids.gov.br/pt-br/noticias/saude-lanca-plano-para-eliminar-hepatite-c-ate2030\#: :text=Um\%20plano\%20pactuado\%20entre\%20o,notifica\%C3\%A7\%C3\%B5es\%20dentre\%20todas\%20as\%20hepatites

Ministério da Saúde. Secretaria de Vigilância em Saúde. Departamento de Vigilância, Prevenção e Controle das IST, do HIV/AIDS e das Hepatites Virais. (2018b). Protocolo Clínico e Diretrizes Terapêuticas para Hepatite $C$ e Coinfecções. http://www.aids.gov.br/system/tdf/pub/2017/64644/ pcdt_hepatitec_07062018_final_web.pdf?file=1\&type=node\&id=64644\&force=1

Ministério da Saúde. Secretaria de Vigilância em Saúde. Departamento de condições crônicas e infecções sexualmente transmissíveis. (2020a). Boletim Epidemiológico de Hepatites Virais - 2020. http://www.aids.gov.br/pt-br/pub/2020/boletim-epidemiologico-hepatites-virais-2020

Ministério da Saúde. Secretaria de Vigilância em Saúde. Departamento de condições crônicas e infecções sexualmente transmissíveis. (2020c). Hepatite D. http://www.aids.gov.br/pt-br/publico-geral/hv/o-que-sao-hepatites/hepatite-d

Ministério da Saúde. Secretaria de Vigilância em Saúde. Departamento de condições crônicas e infecções sexualmente transmissíveis. (2020d). Saúde lança painel informativo sobre tratamento das hepatites $B$ e $C$. http://www.aids.gov.br/pt-br/noticias/saude-lanca-painel-informativo-sobre-tratamento-das-hepatitesb-e-c.

Moher, D., Liberati, A., Tetzlaff, J., \& Altman, D. G. (2015). Principais itens para relatar revisões sistemáticas e meta-análises: a recomendação PRISMA. (T. F. Galvão e T. S. A. Pansani, Trad.). Epidemiologia e Serviços de Saúde,24(2), 335-342. http://scielo.iec.gov.br/scielo.php?script=sci_arttext\&pid=S1679$49742015000200017 \& \operatorname{lng}=\mathrm{pt} \& \operatorname{lng}=\mathrm{pt}$

Moreira, T., \& Areias, J. (2008). Normas de orientação clínica: Hepatite B crônica. Sociedade Portuguesa de gastroenterologia, 14: 187-191. http://www.scielo.mec.pt/pdf/ge/v16n5/v16n5a03.pdf

Motta-Castro, A. R. C., Gomes, S. A., Yoshida, C. F. T., Miguel, J. C., Teles, S. A., \& Martins, R. M. B. (2009). Compliance with and response to hepatitis B vaccination in remaining quilombo communities in Central Brazil. Cadernos de Saúde Pública, 25(4): 738-742. https://doi.org/10.1590/S0102$311 \times 2009000400004$

Mourão, L. C. da S., Alves, L. D. S., Lopes, J. V. S. J., Nunes, L. C. C., \& Medeiros, M. G. F. (2008). Caracterização da hepatite C em pacientes assistidos pelo Programa de Medicamentos de Dispensação em caráter excepcional. Rev. Bras. Farm., 89(3), 226-229.

Oliveira, M. C. R., et al. (2020). Perfil Epidemiológico dos Pacientes com Hepatite C atendidos nos Serviços de Referência do Estado do Piauí. Research, Society and Development, 9(6), e71963457, 2020. 10.33448/rsd-v9i6.3457. https://rsdjournal.org/index.php/rsd/article/view/3457 
Research, Society and Development, v. 10, n. 1, e12510111579, 2021 (CC BY 4.0) | ISSN 2525-3409 | DOI: http://dx.doi.org/10.33448/rsd-v10i1.11579

Oliveira, M. D. S. O. et al. (2006). Soroepidemiologia da infecção pelo vírus da hepatite B e alta taxa de resposta à vacina contra o vírus da hepatite B Butang (B em adolescentes de famílias de baixa renda no Brasil Central. Mem. Inst. Oswaldo Cruz,101(3).

Paraná, R. et al. (2015). Recomendações da SBH para diagnóstico e tratamento das hepatites B e Delta. Simpósio de Hepatologia da Região Norte, Belém. Retirado de: http://sbhepatologia.org.br/pdf/HEPATITE_B_e_DELTA_SBH.pdf

Pereira, A. S., Shitsuka, D. M., Parreira, F. J. \& Shitsuka, R. (2018). Metodologia da pesquisa científica. [e-book]. Santa Maria. Ed. UAB/NTE/UFSM. https://repositorio.ufsm.br/bitstream/handle/1/15824/Lic_Computacao_Metodologia-Pesquisa-Cientifica.pdf?sequence=1

Rodrigues Neto, S. da C. et al. (2020). Epidemiological characterization of notified Hepatitis B cases in the state of Piauí between 2008 and 2018. Research, Society and Development, 9(7), e854975007, 2020. 10.33448/rsd-v9i7.5007. https://rsdjournal.org/index.php/rsd/article/view/5007

Santos, C. M. C., Pimenta, C. A. M., \& Nobre, M. R. C. (2007). The PICO strategy for the research question construction and evidence search. Revista LatinoAmericana de Enfermagem, 15(3), 508-511. https://dx.doi.org/10.1590/S0104-11692007000300023

Schineider, L. R., Pereira, R. P. G., \& Ferraz, L. (2018). A prática baseada em evidência no contexto da Atenção Primária à Saúde. Saúde debate, 42(118). https://doi.org/10.1590/0103-1104201811804

Sousa, L. M. M. de, Marques-Vieira, C. M., Severino, S. S. P., \& Antunes, A. V. (2017). A metodologia da revisão integrativa da literatura em enfermagem. Revista Investigação em Enfermagem, (21): 17-26. http://www.sinaisvitais.pt/images/stories/Rie/RIE21.pdf\#page=17

Sousa, S. R. G. de, Farias, I. C. C., Macedo, P. R. de \& Farias, J. V. C. (2020). Overview of viral hepatitis: a current study. Research, Society and Development, 9(9), e446997443. 10.33448/rsd-v9i9.7443. https://rsdjournal.org/index.php/rsd/article/view/7443

Souza, F. C. et al. (2004). Aspectos clínicos da hepatite C crônica: experiência do ambulatório de hepatites virais/instituto alfa de gastroenterologia/ Hospital das Clínicas da UFMG. Rev Med Minas Gerais, 14(3):136-41. http://rmmg.org/artigo/detalhes/1481

Souza, M. T., Silva, M. D., \& Carvalho, R. (2010). Revisão integrativa: o que é e como fazer. Einstein (São Paulo), 8(1): 102-106. https://doi.org/10.1590/s1679-45082010rw1134

Timóteo, M. V. F, et al. (2020). Epidemiological profile of viral hepatitis in Brazil. Research, Society and Development, 9(6), e29963231. 10.33448/rsdv9i6.3231. https://rsdjournal.org/index.php/rsd/article/view/3231

Whittemore, R., \& Knafl, K. (2005). The integrative review: updated methodology. J Adv Nurs, 52(5), 546-53.10.1111/j.1365-2648.2005.03621.x. https://onlinelibrary.wiley.com/doi/abs/10.1111/j.1365-2648.2005.03621.x

World Health Organization. (2019). Hepatitis Day 2019: Invest in eliminating hepatites. https://www.who.int/hepatitis/strategy2016-2021/ghss-hep/en/

Youshida, O., et al. (2020). Redução do HBsAg pela administração nasal de uma vacinal terapêutica contendo HBsAg e HBcAg (NASCAC) em pacientes com infecção VHB crônica: resultados em seguimento de 18 meses. AASLS Liver Meeting Digital Experience. https://aasld.confex.com/aasld/2020/meetingapp.cgi/Paper/22820 